\title{
Dare to delay? The impacts of adolescent alcohol and marijuana use onset on cognition, brain structure, and function
}

\section{Krista M. Lisdahl *, Erika R. Gilbart, Natasha E. Wright and Skyler Shollenbarger}

Department of Psychology, University of Wisconsin-Milwaukee, Milwaukee, WI, USA

\section{Edited by:}

Remi Martin-Fardon, The Scripps Research Institute, USA

Reviewed by:

Susan F. Tapert, University of California San Diego, USA

Carmelo Mario Vicario, University of Queensland, Italy

*Correspondence:

Krista M. Lisdahl, University of Wisconsin-Milwaukee, 2241 East Hartford Avenue, Milwaukee, WI 53211, USA

e-mail: krista.medina@gmail.com

\begin{abstract}
Throughout the world, drug and alcohol use has a clear adolescent onset (Degenhardt et al., 2008). Alcohol continues to be the most popular drug among teens and emerging adults, with almost a third of 12 th graders and $40 \%$ of college students reporting recent binge drinking (Johnston et al., 2009, 2010), and marijuana (MJ) is the second most popular drug in teens (Johnston et al., 2010). The initiation of drug use is consistent with an overall increase in risk-taking behaviors during adolescence that coincides with significant neurodevelopmental changes in both gray and white matter (Giedd et al., 1996a; Paus et al., 1999; Sowell et al., 1999, 2002, 2004; Gogtay et al., 2004; Barnea-Goraly et al., 2005; Lenroot and Giedd, 2006). Animal studies have suggested that compared to adults, adolescents may be particularly vulnerable to the neurotoxic effects of drugs, especially alcohol and MJ (see Schneider and Koch, 2003; Barron et al., 2005; Monti et al., 2005; Cha et al., 2006; Rubino et al., 2009; Spear, 2010). In this review, we will provide a detailed overview of studies that examined the impact of early adolescent onset of alcohol and MJ use on neurocognition (e.g., Ehrenreich et al., 1999; Wilson et al., 2000; Tapert et al., 2002a; Hartley et al., 2004; Fried et al., 2005; Townshend and Duka, 2005; Medina et al., 2007a; McQueeny et al., 2009; Gruber et al., 2011, 2012; Hanson et al., 2011; Lisdahl and Price, 2012), with a special emphasis on recent prospective longitudinal studies (e.g., White et al., 2011; Hicks et al., 2012; Meier et al., 2012). Finally, we will explore potential clinical and public health implications of these findings.
\end{abstract}

Keywords: adolescence, MRI, alcohol, binge drinking, marijuana, neuropsychology, cognition, age onset

\section{INTRODUCTION}

Throughout the world, drug and alcohol use has a clear adolescent onset (Degenhardt et al., 2008). Alcohol continues to be the most popular drug among teens and young adults, with almost a third of 12th graders and $40 \%$ of college students reporting recent binge drinking (four standard alcohol drinks on an occasion in females and five drinks for males; Johnston et al., 2010, 2011). Further, the majority of teens (58\%) drinkers also use marijuana (MJ) (Martin et al., 1996), contributing to frequent comorbidity between alcohol and MJ use disorders (Agosti et al., 2002). Indeed, MJ is the second most popular drug and is on the rise in teens, with up to $25 \%$ reporting past year use (Johnston et al., 2011). Given this, studies examining the neurocognitive consequences of alcohol and MJ use in youth have gained attention in the scientific literature. This review will present current research regarding the neurocognitive consequences of alcohol, especially binge drinking, and MJ use during the teenage years. Studies utilizing neuropsychological assessment, structural and functional neuroimaging will be reviewed, the impact of teenage drug use onset will be discussed and recommendations for future research will be presented.

Adolescence is a dynamic time marked by increased risk-taking behaviors including substance use (Spear, 2000; Gardener and Steinberg, 2005; Eaton et al., 2006; Casey et al., 2008) that coincide with significant neurodevelopmental changes. Brain regions associated with executive functioning (e.g., problem solving, planning, working memory, and emotional regulation), including the prefrontal cortex (PFC), parietal cortex, and cerebellum, continue to undergo gray matter synaptic pruning into the mid-20s (Giedd et al., 1996a; Sowell et al., 1999, 2002, 2004; Gogtay et al., 2004; Lenroot and Giedd, 2006). White matter volume and integrity increases into the early thirties, yielding improvements in efficient neural conductivity (Giedd et al., 1999; Paus et al., 1999; BarneaGoraly et al., 2005; Jernigan and Gamst, 2005; Nagel et al., 2006). Scholars have emphasized that it may not be the late maturation of the PFC alone that is responsible for increased risk-taking behavior during adolescence, but rather it is due to differential developmental trajectories of the PFC compared to limbic system. During the teen years, the limbic system develops earlier than the PFC (Giedd et al., 1996b; Galvan et al., 2006; Casey et al., 2008). Indeed, as the PFC undergoes neuronal maturation, greater topdown control of the limbic system results in improved inhibitory control and affective processing as an adolescent becomes an adult (Casey et al., 1997, 2005, 2008; Monk et al., 2003; Liston et al., 2006). It should also be noted that there are gender differences in the timing and rate of neurodevelopment (see Lenroot and Giedd, 2010 for review). More specifically, gray matter volumes peak in 
executive centers earlier for girls, indicating that females undergo synaptic pruning earlier and there are greater age-related white matter increases in males; overall, this results in relatively larger brain volumes in boys compared to girls (Giedd et al., 1996b; Nagel et al., 2006; Lenroot et al., 2007; Lenroot and Giedd, 2010). This neuromaturation may represent a sensitive period during which exposure to drugs may have a greater impact on neurocognition compared to adult exposure.

\section{IMPACT OF ADOLESCENT VS. ADULT AGE OF ALCOHOL USE ONSET ON NEUROCOGNITION}

Animal studies have suggested that compared to adults, adolescents may be particularly vulnerable to the neurotoxic effects of early alcohol use onset (AUO) (see Barron et al., 2005; Monti et al., 2005; Spear, 2010 for previous reviews). In humans, addiction specialists have attempted to categorize subtypes of alcohol dependence. One model subdivides alcohol-dependent individuals into Type I and II alcohol-dependent groups (Cloninger, 1987), with Type II alcoholics demonstrating an early AUO (before age 25), earlier treatment attempts, increased novelty seeking, and strong family history of substance-use disorders (SUD; von Knorring et al., 1985; Gilligan et al., 1988; Sullivan et al., 1990). Research examining this typology has revealed that emerging adult AUO ( $<22-25$ years old) is associated with increased childhood behavioral problems, impulsivity, poor decision-making, increased mood disorders, aggressiveness, severity of substanceuse problems, more rapid progression from regular drinking to AUD, unique patterns of cerebral blood flow in the PFC, hyperarousal and poor sensorimotor gating, and increased comorbidity with externalizing disorders and ADHD (Varma et al., 1994; Johnson et al., 2000; Demir et al., 2002; Bjork et al., 2004; Dawe et al., 2004; Dom et al., 2006a,b; Pardo et al., 2007; Chen et al., 2011; Lee et al., 2011; Wilens et al., 2011). Specifically, DeWit et al. (2000) reported that the odds of developing lifetime alcohol dependence increase by $14 \%$ with each increasing year of AUO.

Several of these symptoms, including impulsivity, poor decision making, externalizing symptoms, aggressiveness, sensation seeking are associated with PFC function, which is continuing to develop during the teenage and emerging adult years (see Kolb et al., 2012; Lenroot and Giedd, 2010 for review). Therefore, it has been hypothesized that PFC dysfunction places individuals at risk for early substance use and early AUO further disrupts PFC development, defining a sensitive period for increased neurocognitive effects in adolescents with AUD. In order to test this model, the Minnesota Twin Family Study examined the impact of premorbid personality and adolescent AUO on personality changes through adolescence into emerging adulthood (Hicks et al., 2010, 2012). These investigations found that behavioral disinhibition prior to AUO significantly predicted age of AUO (no onset, adult onset, adolescent onset who stopped using and adolescent onset with continued symptoms of AUD), with increased disinhibition predicting earlier AUO especially in males (Hicks et al., 2010, 2012). Further, early AUO uniquely predicted lack of maturation in behavioral disinhibition compared to other subgroups (Hicks et al., 2012; see Figure 1). Further, this study found that adolescents who stopped drinking had significant recovery in both behavioral disinhibition and negative emotionality (Hicks et al.,

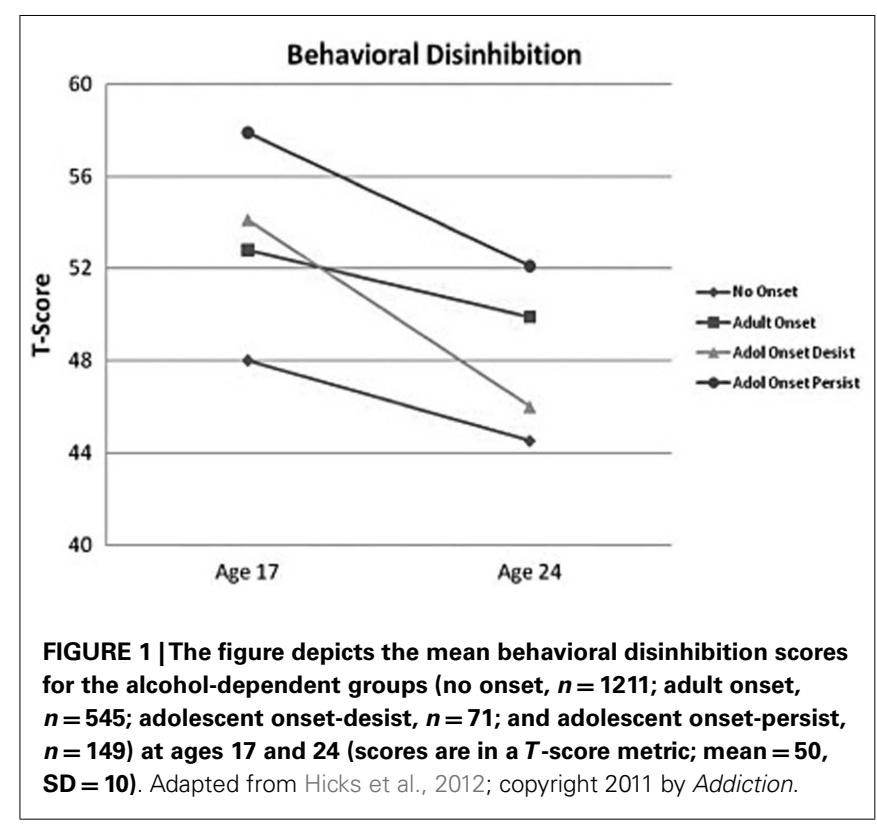

2012), suggesting potential recovery of PFC function with abstinence. Other studies examining the impact of adolescent AUO vs. adult AUO have demonstrated that sensitivity to punishment, disinhibition, and increased likelihood of developing an AUD in teenage AUO (Lyvers et al., 2009, 2011).

\section{BINGE OR HEAVY ALCOHOL USE AND NEUROCOGNITION IN YOUTH}

Given the alarming rates of binge drinking in both teenagers and young adults, especially college students (Johnston et al., $2009,2010)$, it is important to determine whether binge drinking (defined as four standard alcohol drinks on an occasion in females and five drinks for males), even in the absence of an AUD, is associated with cognition and brain changes. This risky drinking pattern has induced neuronal damage and long-lasting behavioral deficits in adolescent and adult animals (Monti et al., 2005; see Barron et al., 2005; Spear, 2010; Coleman et al., 2011). Still, there have been relatively few human studies to date that specifically examine the effects of intermittent binge drinking in adolescents and emerging adults. Thus far, those studies have reported cognitive deficits associated with binge drinking in otherwise healthy teens and emerging adults, including poorer sustained attention (Hartley et al., 2004), memory (Hartley et al., 2004; Scaife and Duka, 2009; Parada et al., 2011), spatial working memory (Townshend and Duka, 2005; Scaife and Duka, 2009), psychomotor speed (Hartley et al., 2004), working memory (Parada et al., 2012), perseverative responding (Parada et al., 2012), and response inhibition and rule acquisition in females (Townshend and Duka, 2005; Scaife and Duka, 2009), although two studies actually found faster motor responding during a visuospatial task (Townshend and Duka, 2005; Scaife and Duka, 2009). Given the high rates of binge drinking in high school and college students, these results are of great concern and these cognitive problems may be, at least in part, to blame for the lower grades seen in heavy drinking students. 
Evidence also suggests underlying structural and functional brain changes associated with binge drinking in adolescents and emerging adults. Using diffusion tensor imaging (DTI), an MRI technique that quantifies white matter integrity, McQueeny et al. (2009) found that teenage binge drinking was associated with significantly reduced white matter quality in several brain regions that connect the brain stem, motor areas, limbic regions, and cortex including the PFC (i.e., the corpus callosum, superior longitudinal fasciculus, corona radiata, internal and external capsules, and commissural, limbic, brainstem, and cortical projection fibers). Greater symptoms of hangover and increased estimated peak BAC estimates were significantly correlated with poorer white matter integrity in white matter tracts connecting the two hemispheres, frontal lobe, and cerebellar tracts.

Alterations in macro-structure of cortical and subcortical gray matter have also been reported. Although binge drinking was not directly assessed, we (Medina et al., 2010) found that increased overall quantity of alcohol use during the past year was significantly related to smaller cerebellar vermis volumes in substanceusing teens. In a follow-up study, our group demonstrated that greater number of drinks per binge in the past 3 months significantly predicted reduced bilateral white and gray matter volumes in the cerebellum in 106 otherwise healthy teens (Lisdahl et al., 2013; see Figure 2). Squeglia et al. (2012) examined cortical thickness in 59 teenagers (ages 16-19) with and without bingedrinking history. Gender significantly moderated the effects of recent binge drinking on PFC and cingulate cortex thickness, with female binge drinkers demonstrating thicker cortices compared to non-drinkers and males demonstrating cortical thinning. In the females, thicker prefrontal cortices were associated with poorer visuospatial, inhibition, and attentional functioning suggesting potential disruption of healthy adolescent PFC pruning in the binge-drinking teens.

Functional changes in brain activation have also been associated with intermittent binge drinking in youth. Event-related potential (ERP) studies have found abnormal signal in anterior and inferior PFC regions to working memory and response inhibition tasks in emerging adults with a history of at least 2 years of intermittent binge drinking (Crego et al., 2010; López-Caneda et al., 2012). Maurage et al. (2009) reported that increases in binge drinking during the first year of college was associated with increasing delays in P1, N2, and P3b latency, areas underlying perceptual, attentional, and executive functioning. This is consistent with Ehlers et al. (2007) who reported smaller P300 amplitudes and latency in adolescents and emerging adults with a binge-drinking history. Research utilizing electroencephalography (EEG) found increased spectral power in delta and fast-beta bands in binge-drinking emerging adults, which is consistent with findings reported in adults with alcohol dependence (Courtney and Polich, 2010).

In a teenage sample, Schweinsburg et al. (2010a) found that binge drinkers had abnormal brain response during a verbal encoding functional magnetic resonance imaging (fMRI) task. Further, unlike the controls, the binge drinkers failed to engage the hippocampus during novel verbal encoding. In a similar sample of 95 adolescents, Squeglia et al. (2011) reported significant gender differences in binge-drinking effects on a spatial working memory task. Female binge drinkers had blunted activation in frontal,
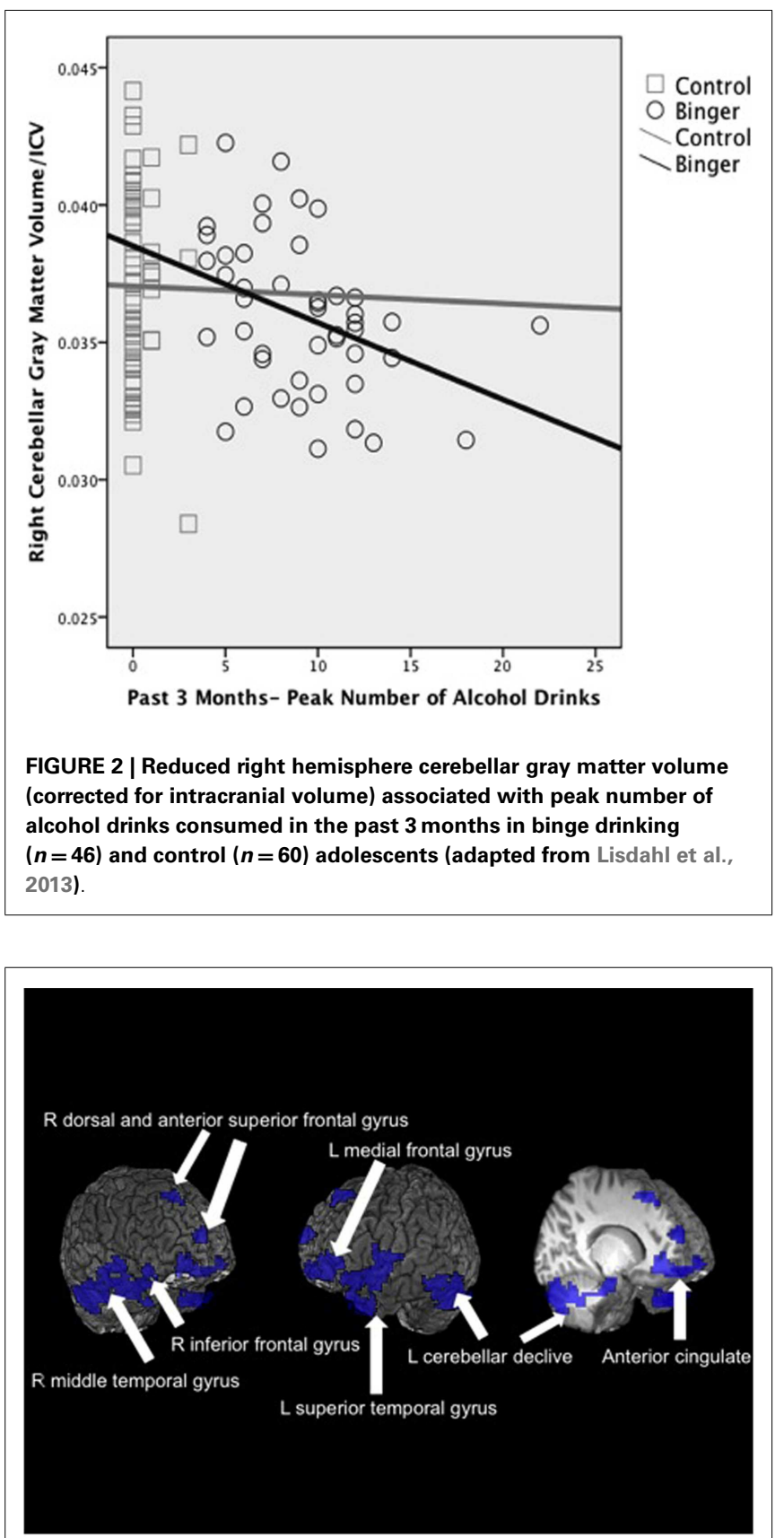

FIGURE 3 | Significant fMRI clusters predicted by the interaction between gender and binge-drinking status $(\boldsymbol{N}=\mathbf{9 5})$. Areas in blue indicate where female binge drinkers demonstrated significantly reduced BOLD response during the spatial working memory task compared to female controls, while male binge drinkers demonstrated increased BOLD response (adapted from Squeglia et al., 2011).

temporal, and cerebellar cortices compared to controls while males demonstrated the opposite pattern (see Figure 3). Other groups have reported blunted amygdala, striatal, and insular activity to emotional cues and decision-making tasks in adolescent binge drinkers compared to social drinkers (Gilman et al., 2012; Xiao et al., 2012). 


\section{NEUROCOGNITIVE CONSEQUENCES OF ALCOHOL USE DISORDERS IN ADOLESCENTS}

Converging lines of evidence suggest that even with substantially shorter periods of exposure, adolescent onset of AUD is associated with neurocognitive deficits. Neuropsychological studies have found that AUD during adolescence and emerging adulthood is associated with poorer verbal memory (Brown et al., 2000; Hanson et al., 2011; Thoma et al., 2011), attention (Tapert and Brown, 1999; Koskinen et al., 2011; Thoma et al., 2011), processing speed (Thoma et al., 2011), visuospatial functioning (Sher et al., 1997; Giancola et al., 1998; Tapert et al., 2002a; Hanson et al., 2011), language (Moss et al., 1994), executive functioning (Hanson et al., 2011; White et al., 2011), and exacerbation of antisocial personality behavior disorder symptoms (Howard et al., 2011). One longitudinal study found that lower levels of impulsive behavior in early adolescence predicted lower rates of AUD in young adulthood; furthermore, they found that past year heavy drinking significantly prospectively predicted additional increases in impulsivity in the following year (White et al., 2011). Withdrawal symptoms seem to be particularly sensitive predictors of cognitive deficits, including poorer visuospatial functioning and memory retrieval (Brown and Tapert, 1999; Brown et al., 2000; Tapert et al., 2002a; Hanson et al., 2011).

Studies utilizing high-resolution MRI have revealed structural abnormalities in teens with AUD, including reduced hippocampal (De Bellis et al., 2000; Nagel et al., 2005; Medina et al., 2007c) and PFC (De Bellis et al., 2005; Medina et al., 2008) volumes, suggesting that adolescent onset of AUD can result in neuronal atrophy, especially in brain regions underlying executive functioning and memory. Using fMRI to assess blood flow changes during cognitive tasks, Tapert et al. (2004) have shown that despite similar behavioral performance on a spatial working memory task, adolescents with AUD have increased brain response in parietal and blunted response in occipital, PFC, and cerebellar regions. Park et al. (2011) found reduced fMRI activation in bilateral frontal and precentral, left superior temporal and parietal cortices, and left cerebellar cortex and increased right uncus activation during a verbal working memory task in teenage males with AUD compared to healthy controls. These results indicate that the adolescent brain may be able to partially compensate for alcohol-induced neuronal insult by relying on other areas to successfully complete the task.

Gender differences in AUD effects have also been reported. Caldwell et al. (2005) found that, after controlling for average BAC, females with AUD demonstrated reduced PFC response compared to gender-matched controls, while the males showed the opposite pattern. Overall, females demonstrated more alcohol-related abnormalities in the PFC compared to males, which was consistent with our structural findings (Medina et al., 2008). Further, young adult women with AUD who underwent a similar fMRI spatial working memory task demonstrated overall blunted brain activation along with poorer behavioral performance (Tapert et al., 2001). In conclusion, emerging adult females with AUD may no longer be able to compensate as effectively as adolescents, demonstrating additional performance decrements with continued alcohol use into early adulthood.

Taken together, these studies suggest that both intermittent binge drinking and the development of AUD can result in significant cognitive, structural, and functional brain changes in both male and female adolescents and emerging adults. Given the fact that approximately $40 \%$ of college students engage in binge drinking, this is a major concern. Combined with other alcoholrelated consequences (e.g., hangover, poor sleep, emotional stress, legal issues, relationship conflict), these cognitive problems may reduce performance in the classroom. Indeed, studies have found that problematic binge drinking has been predictive of a poorer end-of-semester grade point average (Read et al., 2007).

\section{IMPACT OF ADOLESCENT VS. ADULT AGE OF MARIJUANA USE ONSET ON NEUROCOGNITION}

Similar to alcohol findings, preclinical studies have found increased cellular changes associated with THC (delta-9tetrahydrocannabinol; i.e., one of the major psychoactive compounds in MJ) exposure during adolescence compared to adulthood (e.g., Schneider and Koch, 2003; O'Shea et al., 2004; Cha et al., 2006; Quinn et al., 2008; Rubino et al., 2008). Thus far, human findings suggest that earlier MJ use onset (MUO), typically defined as use starting before $16-18$ years old, is associated with more severe cognitive consequences. Converging lines of evidence suggest that regular use of MJ starting before 18 is associated with increased deficits in poorer attention (Ehrenreich et al., 1999), visual search (Huestegge et al., 2002), reduced overall or verbal IQ (Pope et al., 2003; Meier et al., 2012), and executive functioning (Fontes et al., 2011; Solowij et al., 2012). In a thorough study targeting executive functioning, Fontes et al. (2011) compared teenage $(n=49)$ to adult $(n=55)$ MUO matched for IQ, years of daily use, current MJ use, lifetime consumption, and length of abstinence. They found that early onset MJ users had significantly poorer sustained attention, cognitive inhibition, and abstract reasoning (see Figure 4).

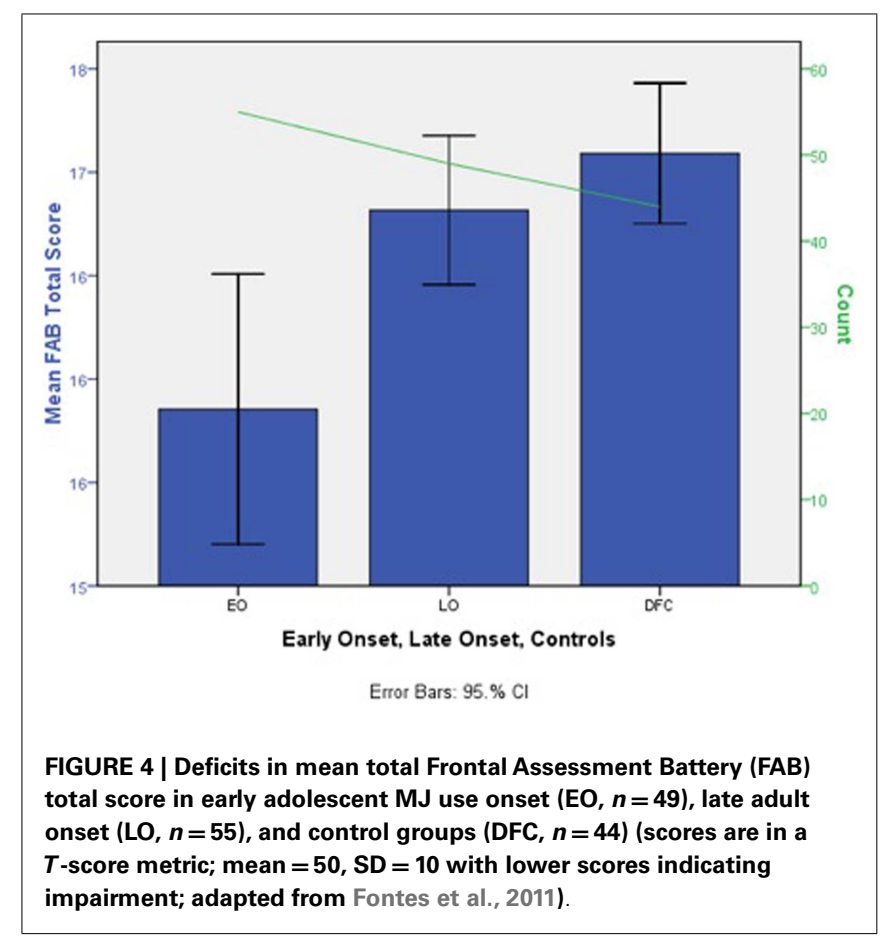


Perhaps the most notable study to date on this topic examined the impact of regular MJ use on IQ and neuropsychological functioning in a longitudinal sample of 1,037 individuals followed from birth to age 38 (Meier et al., 2012). After matching for total number of MJ dependence symptoms, the adolescent MUO demonstrated the most robust change in IQ, who as a group demonstrated a drop from childhood "average" to adult "low-average" full-scale IQ. Indeed, the adolescent MUO individuals never achieved their predicted trajectory in IQ, even with sustained abstinence in adulthood.

Increased structural and functional brain changes associated with adolescent MUO have also been reported. In one of the earliest studies, Wilson et al. (2000) found reduced overall cortical gray matter and increased white matter volumes in participants with adolescent MUO compared to later onset of use. Lopez-Larson et al. (2011) found significant correlations between earlier MUO and decreased right superior PFC cortical thickness in 18 current MJ users. Adolescent onset MJ use has also been linked with increased PFC white matter diffusivity and increased impulsivity compared to later onset in a sample of well-matched MJ users (Gruber et al., 2011; see Figure 5). Functional MRI studies have reported abnormal brain activation abnormalities in early vs. late MUO in PFC and parietal regions (Becker et al., 2010a; Jager et al., 2010; Gruber et al., 2012), although one study did not report age of onset effects on a verbal encoding task (Becker et al., 2010b). [See Figure 6 to examine PFC activation differences between adolescent and adult MUO groups on an inhibitory control fMRI task (Gruber et al., 2012)].

In summary, the brain appears to be particularly vulnerable to adolescent MJ exposure. The PFC continues to mature into early adulthood and may be particularly sensitive to adolescent MJ exposure, as early MUO samples have demonstrated executive dysfunction (Fontes et al., 2011; Gruber et al., 2011; Solowij et al., 2012), structural damage (Churchwell et al., 2010; Gruber et al., 2011; Lopez-Larson et al., 2011), and abnormal brain activation (Jager et al., 2010; Gruber et al., 2012) in the PFC.

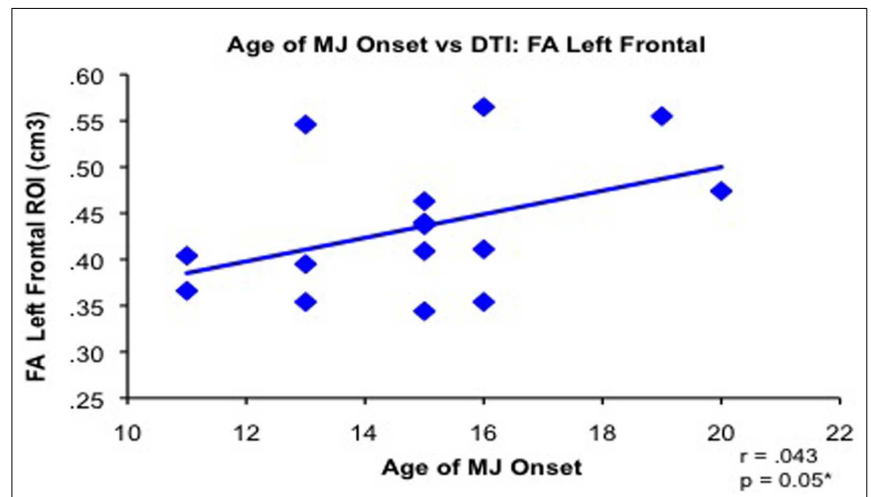

FIGURE 5 | Bivariate relationship between younger age of regular marijuana (MJ) use onset (range 11-20 years of age) and decreased white matter integrity (reduced FA measured by diffusion tensor imaging) in $15 \mathrm{MJ}$ users in the left frontal region of interest (adapted from Gruber et al., 2011).

\section{HEAVY MARIJUANA USE AND NEUROCOGNITION IN ADOLESCENTS AND EMERGING ADULTS}

Consistent with the age of onset data, converging lines of evidence is building to suggest that chronic MJ during the teenage years is associated with neurocognitive deficits. For example, in a longitudinal study following adolescents with SUD over time, Tapert et al. (2002b) found that greater cumulative MJ use over an 8-year follow-up period was associated with poorer attention functioning. Tait et al. (2011) found that after controlling for potentially confounding variables, continued MJ use over an 8year period was associated with decrements in verbal memory. Other studies conducted in adolescents with minimal psychiatric comorbidities have suggested cognitive deficits associated with regular adolescent $\mathrm{MJ}$ use, including processing speed (Fried et al., 2005; Medina et al., 2007a; Lisdahl and Price, 2012), complex attention (Tapert et al., 2002a; Harvey et al., 2007; Medina et al., 2007a; Hanson et al., 2010b; Mathias et al., 2011; Lisdahl and Price, 2012), memory (Schwartz et al., 1989; Fried et al., 2005; Harvey et al., 2007; Medina et al., 2007a; McHale and Hunt, 2008; Hanson et al., 2010b; Solowij et al., 2011; Tait et al., 2011; Thoma et al., 2011), executive functioning, especially cognitive disinhibition (Harvey et al., 2007; Medina et al., 2007a; McHale and Hunt, 2008; Hanson et al., 2010b; Mathias et al., 2011; Gonzalez et al., 2012; Grant et al., 2012; Lisdahl and Price, 2012; Schuster et al., 2012; Solowij et al., 2012), and risky sexual behavior (Schuster et al., 2012).

We (Medina et al., 2007a) compared neuropsychological functioning in a sample of demographically matched healthy controls and MJ-using adolescents without comorbid psychiatric disorders who underwent 28 days of monitored abstinence. After controlling for alcohol use, adolescent MJ users demonstrated deficits in complex attention, verbal story learning, sequencing ability, and slower psychomotor speed compared to controls (Medina et al., 2007a). In a follow-up study that included 59 teens and emerging adult MJ users and controls, we found a similar pattern of cognitive deficits in the MJ users who demonstrated

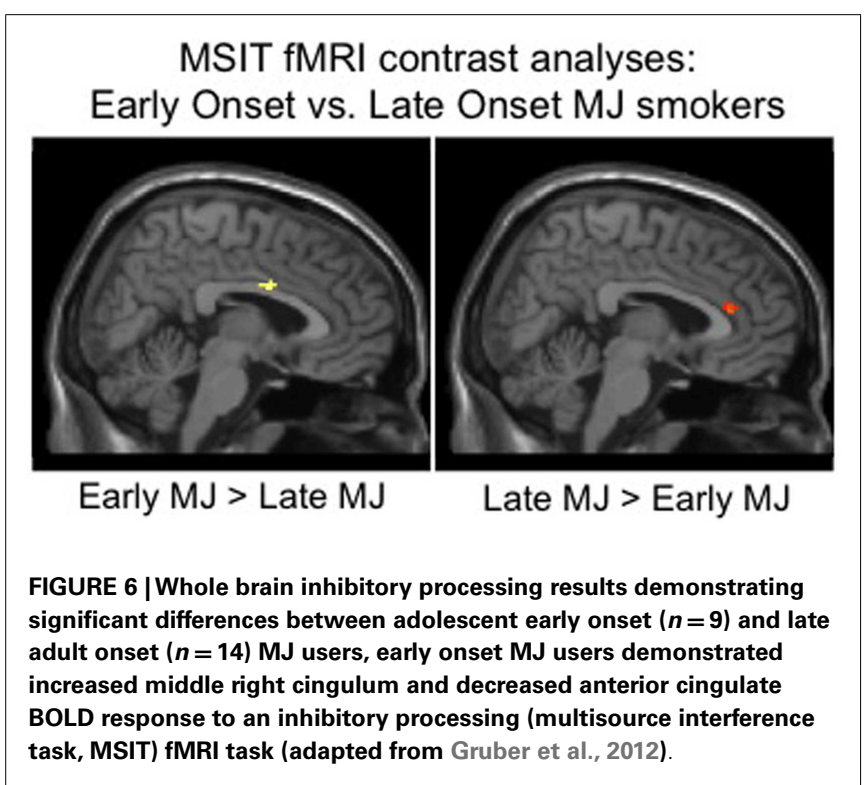


poorer complex attention, slower psychomotor speed, and reduced inhibitory control (Lisdahl and Price, 2012; see Figure 7).

Increasingly, studies utilizing neuroimaging methods to assess brain structure have reported consequences of chronic MJ use in adolescents. Our group has examined brain volumes in a subsample of adolescent MJ users without comorbid psychiatric, developmental, or neurologic conditions (ages 16-19) and healthy controls. Thus far, we found that adolescent MJ users (who also had heavy alcohol use) did not significantly differ from healthy controls in their hippocampal volumes, although correlations between hippocampal volumes and verbal memory were abnormal compared to the controls (Medina et al., 2007c). In 16 MJ users and 16 healthy controls without comorbid psychiatric disorders we found marginal MJ group-by-gender interactions in predicting PFC volume; female MJ users demonstrated comparatively larger volumes, while male users had smaller volumes compared to same-gender controls (Medina et al., 2009). MJ group status and total PFC volume interacted in predicting executive functioning; among the MJ users (especially the girls), larger PFC volumes were associated with poorer executive functioning, while the opposite pattern was seen among the controls, suggesting that larger PFC volumes in the MJ users was detrimental. More recently, increased posterior inferior cerebellar vermis volumes in adolescent MJ users and increased left amygdala volumes in female MJ users were observed compared to controls, suggesting disruption in affective processing circuitry (Jarvis et al., 2008; Medina et al., 2010; McQueeny et al., 2011).

Recently other groups have reported decreased cortical thickness in right caudal middle frontal, bilateral insula, and bilateral superior frontal cortices and increased cortical thickness in lingual, temporal, inferior parietal, and paracentral regions (LopezLarson et al., 2011), decreased right medial orbitofrontal cortex volume (Churchwell et al., 2010), and reduced bilateral hippocampal volumes (Ashtari et al., 2011) in adolescent MJ users without comorbid psychiatric conditions compared to healthy controls.

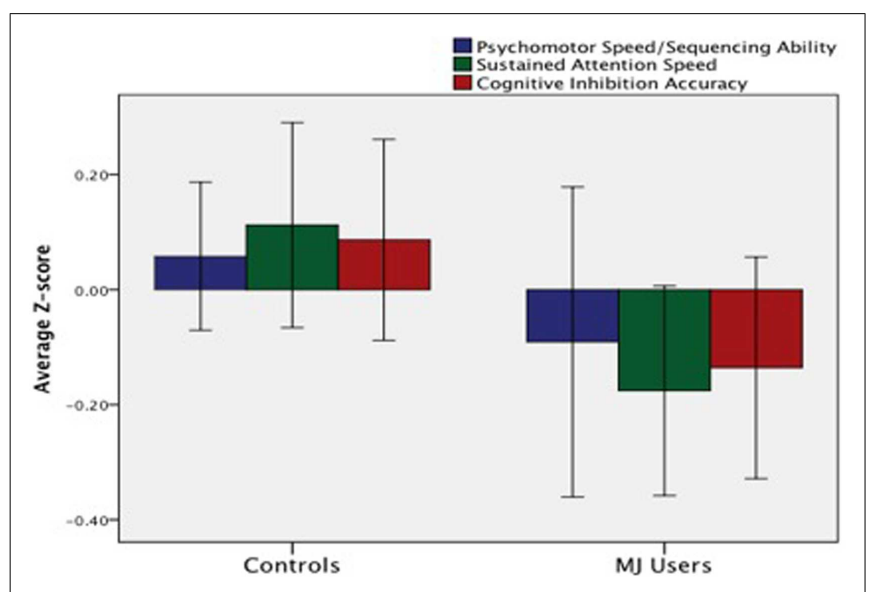

FIGURE 7 | Deficits in mean z-score psychomotor speed, sustained attention, and cognitive inhibition were observed in emerging $\mathbf{M J}$ ( $n=23)$ users compared to normal controls $(n=35)$ following a minimum of 1 week of abstinence (adapted from Lisdahl and Price, 2012).
The above structural alterations were associated with increased executive dysfunction (Medina et al., 2009, 2010; Churchwell et al., 2010), mood symptoms (McQueeny et al., 2011), and verbal memory deficits (Ashtari et al., 2011). Adolescent MJ users have also demonstrated reduced cerebral blood flow in temporal, insular, and $\mathrm{PFC}$ regions after 4 weeks of monitored abstinence, which may also underlie observed cognitive deficits (Jacobus et al., 2012).

Micro-structural and neurochemical abnormalities have also been reported in otherwise healthy adolescent MJ users. Recent use of magnetic resonance spectroscopy (MRS) has revealed neurochemical alterations in adolescent MJ users, including reduced anterior cingulate glutamate, $\mathrm{N}$-acetyl aspartate, creatine, and myo-inositol (Prescot et al., 2011), lower global myoinositol/creatine ratios in subcortical gray matter structures, and reduced myo-inositol in white matter (Silveri et al., 2011) suggesting an early neurochemical response to neuronal toxicity and disruption of microglia activity.

Subtle white matter abnormalities have also been observed in adolescent and emerging adult MJ users. Our group found that increased depressive symptoms in MJ users was associated with smaller global white matter volume (Medina et al., 2007b), suggesting that $\mathrm{MJ}$ use during adolescence may disrupt white matter connections between areas involved in mood regulation. Using DTI, Bava et al. (2009) found that MJ users had significantly poorer white matter integrity, measured by lower fractional anisotropy (FA) in 10 brain regions, especially in regions underlying executive functioning and working memory. Increased FA was also seen in regions underlying vision, suggesting possible over-recruitment of these brain regions in adolescent MJ users compared to controls. With one exception (DeLisi et al., 2006), these results are consistent with other studies that have demonstrated reduced white matter integrity in adolescent and young adult MJ users who initiated use during adolescence (Arnone et al., 2008; Ashtari et al., 2009; Gruber et al., 2011).

There is also converging evidence of inefficient brain activation patterns in adolescent and emerging adult MJ users compared to healthy controls. Studies utilizing fMRI and PET with adolescents have found abnormal PFC, limbic, parietal, and cerebellar activation patterns in $\mathrm{MJ}$ users in response to finger tapping (Lopez-Larson et al., 2012), attentional control (Abdullaev et al., 2010), verbal working memory (Jacobsen et al., 2007; Jager et al., 2010), verbal encoding (Becker et al., 2010b), spatial working memory (Schweinsburg et al., 2008, 2010b; Smith et al., 2010), cognitive inhibition (Tapert et al., 2007), and monetary decisionmaking (Vaidya et al., 2012) tasks. For example, Jager et al. (2010) reported that MJ-using teenage boys (ages 13-19) demonstrated excessive activation in executive (PFC) regions during a verbal working memory task, especially during initial encoding, compared to non-using healthy controls. Consistent with this finding, our laboratory (Tapert et al., 2007) found that after controlling for alcohol use, MJ users demonstrated increased executive (right dorsolateral PFC, bilateral medial frontal), working memory (parietal), and visual (occipital) activation during inhibitory "no-go" trials (i.e., tests of impulse control), compared to normal controls, even though they had marginally poorer performance. Further, teen MJ users with lighter use histories demonstrated the greatest brain activation to both the cognitive inhibition and 
spatial working memory tasks (Tapert et al., 2007; Schweinsburg et al., 2008), while teens with more intense use histories (earlier onset, longer duration, increased lifetime use) had lower activation than controls. A recent functional connectivity study found increased connectivity between PFC and occipitoparietal regions in adolescent MJ users as cognitive control demands increased (Harding et al., 2012). These findings suggests that during initial MJ exposure the brain may successfully compensate by recruiting additional neuronal resources, although this compensation may falter with more problematic and increased MJ use patterns.

Taken together, the above studies suggest that regular MJ use during adolescence may lead to structural changes such as abnormal gray matter pruning patterns and reduced white matter myelination. These changes have been associated with poor neuronal efficiency and poorer cognitive functioning, especially psychomotor speed, executive functioning, emotional control, and learning and memory, even after a month of monitored abstinence. Given the high rates of MJ use in teens and emerging adults, this may mean a large proportion of youth are experiencing cognitive difficulties that may negatively impact their performance. Indeed, we have found increased school difficulty and reduced grades in MJ-using teens (Medina et al., 2007a) (Table 1).

\section{POTENTIAL LIMITATIONS OF THE EXISTING LITERATURE}

It is important to note some limitations of the above research. Although several of the above studies did control for family history of SUD and excluded subjects with Axis I comorbid psychiatric disorders, it is still difficult to determine whether the brain and cognitive abnormalities may have predated the onset of adolescent drug use. Risk factors associated with early drug experimentation (such as poor cognitive inhibition, attention problems, conduct disorder, and family history of SUD) are themselves related to subtle cognitive and brain abnormalities (Aronowitz et al., 1994; Tapert and Brown, 2000; Tapert et al., 2002a; Nigg et al., 2004; Schweinsburg et al., 2004; Hill et al., 2007a,b; Spadoni et al., 2008; Ridenour et al., 2009; Hanson et al., 2010a) and at least some evidence exists suggesting preexisting brain abnormalities predate and predict the onset of substance use (e.g., Cheetham et al., 2012). It is notable, however, that prospective longitudinal studies have provided evidence for additional cognitive and brain abnormalities following the onset of regular alcohol or MJ use that are above and beyond premorbid differences in personality, cognition, and brain structure (Maurage et al., 2009; White et al., 2011; Hicks et al., 2012; Meier et al., 2012). Still, additional longitudinal research in teenagers prior to alcohol and MJ exposure, especially in at-risk comorbid samples, is needed to explore the influence of early drug use on adolescent neurodevelopment.

\section{RECOVERY OF FUNCTION WITH ABSTINENCE? A MESSAGE OF HOPE}

There is even less research available to help determine whether sustained abstinence from alcohol and MJ results in recovery of cognitive functions, although findings to date are hopeful. For example, Hanson et al. (2011) reported that having greater days of abstinence from alcohol and drugs at a 10-year follow-up was associated with improved executive functioning, even controlling for baseline executive functioning and education. In our binge-drinking sample, increased abstinence was associated with larger bilateral cerebellar volumes (Lisdahl et al., 2013). In adolescent MJ users, short-term memory impairments mildly recovered following 3-6 weeks of MJ abstinence (Schwartz et al., 1989; Hanson et al., 2010b), although another study found that adolescent MJ users who abstained for a minimum of 3 months did not demonstrate any cognitive deficits compared to controls (Fried et al., 2005) and in one prospective longitudinal study individuals who began using MJ early never returned to their predicted IQ trajectory even with sustained abstinence in adulthood (Meier et al., 2012). Few fMRI studies have examined recovery of function; in a cross-sectional study, recent MJ users demonstrated increased activation in brain regions underlying executive control and attention, such as the insula and PFC, compared to abstinent ex-users (Schweinsburg et al., 2010b). This preliminary evidence suggests that the inefficient brain response seen in teenage MJ users may begin to normalize after several weeks of abstinence. In sum, these results suggest there may be subtle recovery of cognitive functioning with increasing lengths of abstinence from $\mathrm{MJ}$ and alcohol. Additional research is necessary to examine whether complete recovery of neurocognitive functioning occurs in adolescents with sustained abstinence, or if their neurocognitive trajectory is subtly altered into adulthood. Still, these preliminary findings can be utilized to help increase motivation for abstinence in alcohol and MJ-using youth, as it is expected that with continued abstinence they will experience at least minimal improvements in attention, verbal memory, and neuronal processing speed.

\section{CONCLUSION AND RECOMMENDATIONS INCREASE PSYCHOEDUCATION, SCREENING, AND PERSONALIZED FEEDBACK}

Alarming numbers of adolescents and emerging adults regularly binge drink and use MJ (Johnston et al., 2009, 2010). Animal and human research suggests that adolescence may be a vulnerable period for drug exposure due to critical neurodevelopmental processes that peak during this period. Indeed, adolescents and emerging adults who initiate binge drinking or use $\mathrm{MJ}$ regularly tend to show inferior cognitive skills compared to teens that abstain or use lightly or Compared to individuals who begin substance use in adulthood. This review paper outlined several studies that suggest binge drinking, AUD, and chronic MJ use during the teenage and early adult years results in gray and white matter microand macro-structural abnormalities that are oftentimes correlated with cognitive deficits. Evidence is also mounting that heavy teenage alcohol and MJ use may disrupt brain function, leading to inefficient neuronal activation early on and diminished activation with continued heavy use into emerging adulthood. Additional research is needed to examine the impact of these neurocognitive deficits on treatment outcomes in order to individualize treatment and prevention campaigns (e.g., Feldstein Ewing et al., 2012).

These findings have significant clinical impact as even subtle brain abnormalities and cognitive problems in teens and young adults may lead to important psychosocial consequences. Combined negative impacts of drug and alcohol-related consequences (such as hangovers or emotional stress), sleep deprivation caused by drug use (Cohen-Zion et al., 2009), and acute effects of being intoxicated at school may lead to even more pronounced cognitive problems in current alcohol and MJ-using college students. Youth may miss information presented in class or on the job due to poorer 
Table 1 | Human studies reporting neurocognitive effects of regular alcohol and marijuana exposure in adolescents and emerging adults (organized by cognitive, structural, or functional consequences and clustered according to functional outcomes).

\begin{tabular}{|c|c|c|c|c|}
\hline $\begin{array}{l}\text { Alcohol use } \\
\text { disorder studies }\end{array}$ & $\begin{array}{l}\text { Teenage onset } \\
\text { worse? }\end{array}$ & Cognitive deficits & $\begin{array}{l}\text { Brain structure } \\
\text { abnormalities }\end{array}$ & Brain function abnormalities \\
\hline Hicks et al. (2012) & Yes & $\uparrow$ behavioral disinhibition & & \\
\hline Lyvers et al. (2009) & Yes & $\begin{array}{l}\uparrow \text { reward sensitivity; } \\
\text { disinhibition }\end{array}$ & & \\
\hline Lyvers et al. (2011) & Yes & $\begin{array}{l}\uparrow \text { reward sensitivity; } \\
\text { disinhibition }\end{array}$ & & \\
\hline Brown et al. (2000) & & $\downarrow$ verbal memory & & \\
\hline Hanson et al. (2011) & & $\downarrow$ verbal memory & & \\
\hline Thoma et al. (2011) & & $\downarrow$ processing speed & & \\
\hline Koskinen et al. (2011) & & $\downarrow$ attention & & \\
\hline $\begin{array}{l}\text { Tapert and Brown } \\
\text { (1999) }\end{array}$ & & $\downarrow$ attention & & \\
\hline Giancola et al. (1998) & & $\downarrow$ visuospatial ability & & \\
\hline Sher et al. (1997) & & $\downarrow$ visuospatial ability & & \\
\hline Tapert et al. (2002a) & & $\downarrow$ visuospatial ability & & \\
\hline Moss et al. (1994) & & $\downarrow$ language & & \\
\hline White et al. (2011) & & $\begin{array}{l}\downarrow \text { executive functioning, } \\
\text { inhibition }\end{array}$ & & \\
\hline Howard et al. (2011) & & $\begin{array}{l}\uparrow \text { antisocial personality } \\
\text { disorder symptoms }\end{array}$ & & \\
\hline De Bellis et al. (2000) & & & $\downarrow H C$ volume & \\
\hline Nagel et al. (2005) & & & $\downarrow$ left HC volume & \\
\hline Medina et al. (2007a) & & & $\downarrow$ left HC volume & \\
\hline Medina et al. (2010) & & & $\begin{array}{l}\downarrow \text { cerebellar vermis GM } \\
\text { volume }\end{array}$ & \\
\hline De Bellis et al. (2005) & & & $\downarrow$ PFC volume & \\
\hline Medina et al. (2008) & & & $\downarrow$ PFC volume & \\
\hline Caldwell et al. (2005) & & & & $\begin{array}{l}\text { Females: } \downarrow \text { superior frontal, temporal, } \\
\text { cingulate, fusiform BOLD response } \\
\text { during SWM task; Males opposite } \\
\text { pattern. }\end{array}$ \\
\hline Park et al. (2011) & & & & $\begin{array}{l}\downarrow \text { PFC, temporal, parietal, cerebellar, } \uparrow \\
\text { uncus fMRI BOLD during WWM task in } \\
\text { males }\end{array}$ \\
\hline Tapert et al. (2004) & & & & $\begin{array}{l}\downarrow \text { PFC, occipital, cerebellar, } \uparrow \text { parietal } \\
\text { fMRI BOLD during SWM task }\end{array}$ \\
\hline Tapert et al. (2001) & & & & $\begin{array}{l}\downarrow P F C \text {, parietal fMRI BOLD during } \\
\text { SWM task in females }\end{array}$ \\
\hline
\end{tabular}


Table 1 | Continued

\begin{tabular}{|c|c|c|c|}
\hline $\begin{array}{l}\text { Binge-drinking } \\
\text { studies }\end{array}$ & $\begin{array}{l}\text { Teenage onset } \\
\text { worse? }\end{array}$ & Cognitive findings & $\begin{array}{l}\text { Brain structure } \\
\text { findings }\end{array}$ \\
\hline Hartley et al. (2004) & & $\begin{array}{l}\downarrow \text { sustained attention, memory, } \\
\text { psychomotor speed }\end{array}$ & \\
\hline Parada et al. (2011) & & $\begin{array}{l}\downarrow \text { verbal memory, working } \\
\text { memory, perseverative } \\
\text { responding }\end{array}$ & \\
\hline $\begin{array}{l}\text { Scaife and Duka } \\
\text { (2009) }\end{array}$ & & $\begin{array}{l}\downarrow \text { verbal memory, SWM, } \\
\text { cognitive inhibition }\end{array}$ & \\
\hline Townshend and & & $\downarrow$ SWM, cognitive inhibition, rule & \\
\hline Duka (2005) & & acquisition & \\
\hline Lisdahl et al. (2013) & & & $\begin{array}{l}\downarrow \text { L/R cerebellar GM and WM } \\
\text { volumes }\end{array}$ \\
\hline $\begin{array}{l}\text { McQueeny et al. } \\
\text { (2009) }\end{array}$ & & & $\begin{array}{l}\downarrow \text { white matter integrity DTI } \\
\text { (CC, superior longitudinal } \\
\text { fasciculus, corona radiate, } \\
\text { internal/external capsules) }\end{array}$ \\
\hline Squeglia et al. (2012) & & & $\begin{array}{l}\text { Females: } \uparrow \text { PFC/cingulate } \\
\text { thickness; Males: } \downarrow \\
\text { PFC/cingulate thickness }\end{array}$ \\
\hline
\end{tabular}

Courtney and Polich

(2010)

Crego et al. (2010)

Ehlers et al. (2007)

López-Caneda et al.

(2012)

Maurage et al.

(2009)

Gilman et al. (2012)

Schweinsburg et al.

(2010a)

Squeglia et al. (2011)

PFC/cingulate thickness

Brain function findings

Xiao et al. (2012)

$\uparrow$ EEG spectral power in delta and fast beta bands

$\downarrow$ ERP in anterior/inferior PFC

$\downarrow$ P300 ERP amplitude

$\uparrow$ go-P3 ERP in right inferior PFC

$\downarrow$ P1, N2, P3b ERP latency

$\downarrow$ NAcc, amygdala fMRI BOLD during emotional cues task after consuming alcohol

$\downarrow$ HC fMRI BOLD during verbal encoding task

Females: $\downarrow$ PFC, temporal, and cerebellar BOLD during SWM fMRI task. Males: opposite pattern.

$\uparrow$ amygdala, insula fMRI BOLD during IGT task

\section{Brain function findings}

\begin{tabular}{lll}
\hline $\begin{array}{ll}\text { Marijuana } \\
\text { studies }\end{array}$ & $\begin{array}{l}\text { Teenage onset } \\
\text { worse? }\end{array}$ & Cognitive find \\
\hline Meier et al. (2012) & Yes & $\downarrow$ IO \\
Pope et al. (2003) & Yes & $\downarrow$ IO \\
$\begin{array}{l}\text { Ehrenreich et al. } \\
\text { (1999) }\end{array}$ & Yes & $\downarrow$ attention \\
\end{tabular}

Brain structure findings 
Table 1 | Continued

\begin{tabular}{|c|c|c|c|c|}
\hline $\begin{array}{l}\text { Marijuana } \\
\text { studies }\end{array}$ & $\begin{array}{l}\text { Teenage onset } \\
\text { worse? }\end{array}$ & Cognitive findings & $\begin{array}{l}\text { Brain structure } \\
\text { findings }\end{array}$ & Brain function findings \\
\hline $\begin{array}{l}\text { Huestegge et al. } \\
\text { (2002) }\end{array}$ & Yes & $\downarrow$ visual search & & \\
\hline Fontes et al. (2011) & Yes & $\downarrow$ executive functioning & & \\
\hline Solowij et al. (2012) & Yes & $\downarrow$ executive functioning & & \\
\hline $\begin{array}{l}\text { Churchwell et al. } \\
\text { (2010) }\end{array}$ & Yes & & $\downarrow$ PFC volume & \\
\hline Gruber et al. (2011) & Yes & $\uparrow$ impulsivity & $\downarrow W M$ integrity in PFC & \\
\hline $\begin{array}{l}\text { Lopez-Larson et al. } \\
\text { (2011) }\end{array}$ & Yes & & $\downarrow$ superior PFC thickness & \\
\hline Wilson et al. (2000) & Yes & & $\downarrow$ total GM; $\uparrow$ total WM & \\
\hline Becker et al. (2010a) & Yes & & & $\begin{array}{l}\uparrow \text { left superior PFC fMRI BOLD during } \\
\text { working memory task in early onset }\end{array}$ \\
\hline Becker et al. (2010b) & No & & & $\begin{array}{l}\uparrow \text { left parahippocampal gyrus, fMRI BOLD } \\
\text { during learning task in all MJ users }\end{array}$ \\
\hline Gruber et al. (2012) & Yes & & & $\begin{array}{l}\downarrow \text { anterior cingulate fMRI BOLD during } \\
\text { inhibition task in early onset }\end{array}$ \\
\hline Jager et al. (2010) & Yes & & & $\begin{array}{l}\uparrow \text { PFC fMRI BOLD during novel stimuli } \\
\text { presentation in working memory task in } \\
\text { early onset }\end{array}$ \\
\hline Fried et al. (2005) & & $\begin{array}{l}\downarrow \text { processing speed verbal } \\
\text { memory }\end{array}$ & & \\
\hline Hanson et al. (2010b) & & $\begin{array}{l}\downarrow \text { complex attention, verbal } \\
\text { memory }\end{array}$ & & \\
\hline Harvey et al. (2007) & & $\begin{array}{l}\downarrow \text { complex attention, verbal } \\
\text { memory; executive functioning }\end{array}$ & & \\
\hline $\begin{array}{l}\text { Lisdahl and Price } \\
\text { (2012) }\end{array}$ & & $\begin{array}{l}\downarrow \text { complex attention processing } \\
\text { speed, sequencing ability, } \\
\text { cognitive inhibition }\end{array}$ & & \\
\hline Medina et al. (2007a) & & $\begin{array}{l}\downarrow \text { complex attention processing } \\
\text { speed, verbal memory, } \\
\text { sequencing ability }\end{array}$ & & \\
\hline Mathias et al. (2011) & & $\begin{array}{l}\downarrow \text { complex attention, executive } \\
\text { functioning }\end{array}$ & & \\
\hline Tapert et al. (2002a) & & $\downarrow$ complex attention & & \\
\hline $\begin{array}{l}\text { McHale and Hunt } \\
\text { (2008) }\end{array}$ & & $\begin{array}{l}\downarrow \text { verbal memory, executive } \\
\text { functioning }\end{array}$ & & \\
\hline $\begin{array}{l}\text { Schwartz et al. } \\
\text { (1989) }\end{array}$ & & $\downarrow$ verbal memory & & \\
\hline Solowij et al. (2011) & & $\begin{array}{l}\downarrow \text { verbal memory; executive } \\
\text { functioning }\end{array}$ & & \\
\hline
\end{tabular}


Table 1 | Continued

\begin{tabular}{|c|c|c|c|}
\hline $\begin{array}{l}\text { Marijuana } \\
\text { studies }\end{array}$ & $\begin{array}{l}\text { Teenage onset } \\
\text { worse? }\end{array}$ & Cognitive findings & $\begin{array}{l}\text { Brain structure } \\
\text { findings }\end{array}$ \\
\hline Tait et al. (2011) & & $\downarrow$ verbal memory & \\
\hline Thoma et al. (2011) & & $\downarrow$ verbal memory & \\
\hline Gonzalez et al. (2012) & & $\downarrow$ executive functioning & \\
\hline Grant et al. (2012) & & $\downarrow$ executive functioning & \\
\hline Schuster et al. (2012) & & $\begin{array}{l}\downarrow \text { executive functioning; } \uparrow \text { risky } \\
\text { sexual behavior }\end{array}$ & \\
\hline $\begin{array}{l}\text { McQueeny et al. } \\
\text { (2011) }\end{array}$ & & $\uparrow$ depressive symptoms & Females: $\uparrow$ left amygdala \\
\hline Medina et al. (2007b) & & $\uparrow$ depressive symptoms & $\downarrow$ global WM \\
\hline Jarvis et al. (2008) & & & $\uparrow$ amygdala volume \\
\hline Ashtari et al. (2011) & & $\downarrow$ verbal memory & $\downarrow \mathrm{HC}$ volume \\
\hline Medina et al. (2007b) & & & $\uparrow$ left HC volume \\
\hline $\begin{array}{l}\text { Churchwell et al. } \\
\text { (2010) }\end{array}$ & & $\downarrow$ executive functioning & $\begin{array}{l}\downarrow \text { right medial orbitofrontal } \\
\text { cortex volume }\end{array}$ \\
\hline $\begin{array}{l}\text { Lopez-Larson et al. } \\
\text { (2011) }\end{array}$ & & & $\begin{array}{l}\downarrow \text { right caudal, middle frontal, } \\
\text { inula, superior frontal } \\
\text { thickness; } \uparrow \text { lingual, temporal, } \\
\text { inferior parietal, paracentral } \\
\text { thickness }\end{array}$ \\
\hline Medina et al. (2010) & & $\downarrow$ executive functioning & $\begin{array}{l}\uparrow \text { inferior cerebellar vermis } \\
\text { volume }\end{array}$ \\
\hline Medina et al. (2009) & & $\downarrow$ executive functioning & $\begin{array}{l}\text { Females: } \uparrow \text { inferior PFC } \\
\text { volume }\end{array}$ \\
\hline Arnone et al. (2008) & & & $\begin{array}{l}\downarrow \text { WM integrity (corpus } \\
\text { collosum) }\end{array}$ \\
\hline Ashtari et al. (2009) & & & $\begin{array}{l}\downarrow \text { WM integrity (arcuate } \\
\text { fasciculus) }\end{array}$ \\
\hline Bava et al. (2009) & & & $\begin{array}{l}\downarrow \text { white matter integrity in } 10 \\
\text { regions (especially PFC, } \\
\text { parietal cortex); } \uparrow \text { WM } \\
\text { integrity in occipital cortex }\end{array}$ \\
\hline DeLisi et al. (2006) & & & No WM differences detected \\
\hline Prescot et al. (2011) & & & $\begin{array}{l}\downarrow \text { ACC glutamate, } \mathrm{N} \text {-acetyl } \\
\text { aspartate, creatine, } \\
\text { myo-inositol }\end{array}$ \\
\hline Silveri et al. (2011) & & & $\begin{array}{l}\downarrow \text { subcortical GM } \\
\text { myo-inositol/creatine; WM } \\
\text { myo-inositol }\end{array}$ \\
\hline
\end{tabular}

$\uparrow$ PFC FMRI BOLD during attentional control task

(Continued) 
Table 1 | Continued

\begin{tabular}{|c|c|c|c|c|}
\hline $\begin{array}{l}\text { Marijuana } \\
\text { studies }\end{array}$ & $\begin{array}{l}\text { Teenage onset } \\
\text { worse? }\end{array}$ & Cognitive findings & $\begin{array}{l}\text { Brain structure } \\
\text { findings }\end{array}$ & Brain function findings \\
\hline Harding et al. (2012) & & & & $\begin{array}{l}\uparrow \text { PFC and occipitoparietal connectivity as } \\
\text { task demands increase }\end{array}$ \\
\hline Jacobsen et al. & & & & $\downarrow$ PFC, parietal connectivity during verbal \\
\hline$(2007)$ & & & & $\begin{array}{l}\text { working memory task while undergoing } \\
\text { nicotine withdrawal }\end{array}$ \\
\hline Jacobus et al. (2012) & & & & $\begin{array}{l}\downarrow \text { cerebral blood flow in temporal lobe, } \\
\text { insula, and PFC }\end{array}$ \\
\hline Jager et al. (2010) & & & & $\begin{array}{l}\uparrow P F C \text { fMRI BOLD during verbal encoding } \\
\text { task in males }\end{array}$ \\
\hline $\begin{array}{l}\text { Lopez-Larson et al. } \\
\text { (2012) }\end{array}$ & & & & $\begin{array}{l}\downarrow \text { cingulate gyrus, cerebellar fMRI BOLD } \\
\text { during finger tapping task }\end{array}$ \\
\hline $\begin{array}{l}\text { Schweinsburg et al. } \\
(2008)\end{array}$ & & & & $\begin{array}{l}\downarrow \text { PFC, occipital, } \uparrow \text { parietal fMRI BOLD } \\
\text { during SWM task }\end{array}$ \\
\hline $\begin{array}{l}\text { Schweinsburg et al. } \\
(2010 b)\end{array}$ & & & & $\begin{array}{l}\uparrow P F C \text {, insula, } \downarrow \text { precentral fMRI BOLD } \\
\text { during SWM task in recent MJ users vs. } \\
\text { abstinent users }\end{array}$ \\
\hline Smith et al. (2010) & & & & $\begin{array}{l}\uparrow \text { inferior, middle PFC fMRI BOLD during } \\
\text { SWM task }\end{array}$ \\
\hline Tapert et al. (2007) & & & & $\begin{array}{l}\uparrow \text { PFC, parietal, occipital fMRI BOLD } \\
\text { during inhibitory processing task }\end{array}$ \\
\hline Vaidya et al. (2012) & & & & $\begin{array}{l}\uparrow \text { ventral medial PFC, cerebellar PET rCBF } \\
\text { during IGT task }\end{array}$ \\
\hline
\end{tabular}

Teenage onset worse? = "yes" - analysis revealed that teenage age of onset $(<16,17$, or 18 years of age) was associated with significantly poorer neurocognitive outcome; if "no" - onset was not associated with outcome; if left blank - age of onset analysis was not conducted in this study. GM, gray matter; WM, white matter; PFC, prefrontal cortex; HC, hippocampus; SWM, spatial working memory; VWM, verbal working memory; IGT, lowa Gambling task.

processing speed, initial learning, complex attention, and working memory. Indeed, researchers have found that substance-induced cognitive disadvantage may lead to lower than expected school performance, increased school problems, risky decision-making, and poorer emotional regulation (Lynskey and Hall, 2000; Medina et al., 2007a; Kloos et al., 2009).

It is critical to disseminate these findings to high school and college students, young military enlistees, therapists, teachers, child psychiatrists, pediatricians, and parents to help minimize regular alcohol and MJ consumption in youth. Fortunately, high-quality psychoeducation materials regarding the effects of alcohol and drugs on the brain, including pamphlets designed for teens and young adults, are available at no cost through the National Institute on Drug Abuse ${ }^{1}$, the National Institute on Alcohol Abuse and Alcoholism $^{2}$, teen-centered sites like the www.thecoolspot.gov and www.drugfreeamerica.org, and university websites such as Teen $\mathrm{Safe}^{3}$, which has an excellent parent resource center. Still, we may improve outcomes by providing more personalized feedback about

\footnotetext{
${ }^{1}$ www.nida.nih.gov

${ }^{2}$ www.niaaa.nih.gov

${ }^{3}$ www.Teen-Safe.org
}

drugs and alcohol health effects (see Larimer and Cronce, 2007). To date, however, no systematic individualized feedback programs have integrated information regarding the effects of drugs on neurocognition. At this time, more global feedback focused on group, or normative, performance results could be integrated. For example, adolescents who engage in heavy drinking could be told that, "Teens who drank more than nine alcohol drinks in one occasion had 1.8 cubic centimeters less cerebellar brain volume than teens who drank three or fewer drinks when drinking, on average. The cerebellum is important for coordination and thinking skills" (Lisdahl et al., 2013). Youth who engage in weekly MJ use could be told "even with similar verbal intelligence and reading ability, MJ users scored more than half a standard deviation lower on an executive functioning task, achieved a half-point lower GPA, and were more likely to demonstrate behavioral problems in school (26 vs. $0 \%$ ) compared to peers who did not regularly use MJ" (Medina et al., 2007a). This normative feedback could be developed further and disseminated more globally by services aimed at health education and drug prevention in youth. One potential opportunity is to integrate this information more thoroughly into existing computerized programs such as CRAFFT screening tool (Knight et al., 2002), which asks six questions and reveals a teen's risk for 
problematic, abusive, or dependent use patterns ${ }^{4}$. After retrieving your score, the computerized program provides potential impact of your use on health, including brain function. After taking the screening tool, physicians and therapists could then utilize brief motivational interviewing to help educate youth further about the negative effects of alcohol and MJ use on the brain. Taken further, therapists could order neuropsychological testing and give truly individualized feedback regarding the student's cognitive functioning.

\section{DEVELOP INTERVENTIONS TO IMPROVE NEUROCOGNITION: EXERCISE?}

Treatments that may reverse substance-induced neurocognitive damage in youth are needed. Some potential candidates include cognitive rehabilitation (see Macher and Earleywine, 2012) or exercise. In animals, physical activity has been linked to decreased inflammatory response and oxidative stress at moderate levels (Radak et al., 2007; Sim et al., 2008; Sakurai et al., 2009), increased c-FOS expression (Sim et al., 2008), and improved catecholaminergic (dopamine, norepinephrine, and epinephrine) function in brain regions including the PFC (Heyes et al., 1985; Elam et al., 1987; Chaouloff, 1989; Dunn and Dishman, 1991; Dunn et al., 1996; Waters et al., 2005). Several human studies have concluded that activity and cardiorespiratory fitness have positive effects on brain health and neuronal plasticity, although the vast majority of the studies have been conducted in older adults (Brisswalter et al., 2002; Cotman and Berchtold, 2002; Colcombe and Kramer, 2003; Colcombe et al., 2004, 2006; Heyn et al., 2004; Kramer and Erickson, 2007; Boecker et al., 2008; Hillman et al., 2008; Ma, 2008; Ploughman, 2008; Coelho et al., 2013). Given ongoing neurodevelopment and fewer comorbid problems like vascular disease in youth, these findings may not directly generalize to teens.

Although research has shown that physical activity is associated with improved mood, decreased drug use, and increased grade point in adolescents (Winnail et al., 1995; Field et al., 2001; Audrain-McGovern et al., 2006), very few studies have directly examined the neurocognitive benefits of physical activity in adolescents. In meta-analyses (Etnier et al., 1997; Sibley and Etnier, 2003), low to large (0.24-0.77) effect sizes for the impact of activity on perceptual skills, academic achievement, and verbal tests in adolescents have been reported; however, higher-order executive functioning or brain structure were not measured. Research examining the impact of acute effects of exercise or improved fitness in healthy emerging adults have found superior executive control (Dustman et al., 1990; Hillman et al., 2003; Themanson

${ }^{4}$ http://www.ceasar.org/teens/test.php

\section{REFERENCES}

Abdullaev, Y., Posner, M. I., Nunnally, R., and Dishion, T. J. (2010). Functional MRI evidence for inefficient attentional control in adolescent chronic cannabis abuse. Behav. Brain Res. 215, 45-57. doi:10.1016/j.bbr.2010.06.023

Agosti, V., Nunes, E., and Levin, F. (2002). Rates of psychiatric comorbidity among

and Hillman, 2006; Themanson et al., 2006; Ferris et al., 2007), increased cerebral blood flow (Pereira et al., 2007; Timinkul et al., 2008), and improved white matter integrity (Marks et al., 2007). In sum, there is at least preliminary evidence that increased physical activity is associated improved neurocognitive functioning, especially executive functioning, in otherwise healthy young adults without cerebrovascular disease. Perhaps most promising, recent research has suggested that exercise interventions may reverse neuronal damage in binge drinking adolescent animals (Helfer et al., 2009) and brief interventions to increase exercise may help reduce drug use and increase physical activity in adolescents (Werch et al., 2005). Additional research is needed to examine how physical activity impacts neurocognition in adolescent drug users, but there is optimism that this is an ideal time to intervene. Indeed, physical activity during the this sensitive stage of ongoing neurodevelopment (ages 15-25) has been associated with superior information processing in elderly men, after controlling for their current level of activity (Dik et al., 2003). Therefore, there is an opportunity to intervene early during the school years to reduce drug use, reverse neurocognitive damage, and perhaps instill lifelong exercise habits that may actually improve aging.

\section{SUMMARY: DELAY THE ONSET}

Adolescence has been named the "gateway to adult health outcomes" (Raphael, 2013) and presents a golden opportunity for public policy intervention to significantly improve health outcomes that last throughout adulthood. However, this sensitive period is also associated with the onset of binge drinking and MJ use, which negatively impacts cognition, brain structure, and function in otherwise healthy teens and young adults. Early age of onset (before age 18) has been linked with the greatest neurocognitive deficits. Therefore, general psychoeducation coupled with personalized feedback regarding effects of chronic drug use on thinking abilities and brain health need to be integrated into current prevention, screening, and treatment programs. Interventions geared toward lowering alcohol and drug exposure in teens and young adults that have shown evidence of efficacy need to be implemented more aggressively in schools and college campuses to not only reduce symptoms of drug abuse and dependence, but delay the onset of regular use from early teen years to early adult years in order to prevent long-term neuronal damage and ensure optimal brain health and cognitive functioning in youth.

\section{ACKNOWLEDGMENTS}

During manuscript preparation, Dr. Lisdahl was supported by the NIDA-funded grant R01DA030354.

spatial statistics. Neuroimage 41, 1067-1074. doi:10.1016/j.neuroimage. 2008.02.064

Aronowitz, B., Liebowitz, M. R., Hollander, E., Fazzini, E., Durlach-Misteli, C., Frenkel, M., et al. (1994). Neuropsychiatric and neuropsychological findings in conduct disorder and attention-deficit hyperactivity disorder. J. Neuropsychiatry Clin. Neurosci. 6, 245-249.
Ashtari, M., Avants, B., Cyckowski, L., Cervellione, K. L., Roofeh, D., Cook, P., et al. (2011). Medial temporal structures and memory functions in adolescents with heavy cannabis use. J. Psychiatr. Res. 45, 1055-1066. doi:10.1016/j.jpsychires.2011.01.004 Ashtari, M., Cervellione, K., Cottone, J., Ardekani, B. A., Sevy, S., and Kumra, S. (2009). Diffusion abnormalities in adolescents and young adults 
with a history of heavy cannabis use. J. Psychiatr. Res. 43, 189-204. doi:10.1016/j.jpsychires.2008.12.002 Audrain-McGovern, J., Rodriguez, D., Wileyto, E. P., Schmitz, K. H., and Shields, P. G. (2006). Effect of team sport participation on genetic predisposition to adolescent smoking progression. Arch. Gen. Psychiatry 63, 433-441. doi:10.1001/archpsyc.63.4.433

Barnea-Goraly, N., Menon, V., Eckert, M., Tamm, L., Bammer, R., Karchemskiy, A., et al. (2005). White matter development during childhood and adolescence: a crosssectional diffusion tensor imaging study. Cereb. Cortex 15, 1848-1854. doi:10.1093/cercor/bhi062

Barron, S., White, A., Swartzwelder, H. S., Bell, R. L., Rodd, Z. A., Slawecki, C. J., et al. (2005). Adolescent vulnerabilities to chronic alcohol or nicotine exposure: findings from rodent models. Alcohol. Clin. Exp. Res. 29, 1720-1725. doi:10.1097/ 01.alc.0000179220.79356.e5

Bava, S., Frank, L. R., McQueeny, T., Schweinsburg, B. C., Schweinsburg, A. D., and Tapert, S. F. (2009). Altered white matter microstructure in adolescent substance users. Psychiatry Res. 173, 228-237. doi:10.1016/j.pscychresns. 2009. 04.005

Becker, B., Wagner, D., GouzoulisMayfrank, E., Spuentrup, E., and Daumann, J. (2010a). The impact of early-onset cannabis use on functional brain correlates of working memory. Prog. Neuropsychopharmacol. Biol. Psychiatry 34, 837-845. doi:10.1016/j.pnpbp.2010.03.032

Becker, B., Wagner, D., GouzoulisMayfrank, E., Spuentrup, E., and Daumann, J. (2010b). Altered parahippocampal functioning in cannabis users is related to the frequency of use. Psychopharmacology (Berl.) 209, 361-374. doi:10.1007/s00213-010-1805-z

Bjork, J. M., Hommer, D. W., Grant, S. J., and Danube, C. (2004). Impulsivity in abstinent alcoholdependent patients: relation to control subjects and type 1-/type 2like traits. Alcohol 34, 133-150. doi:10.1016/j.alcohol.2004.06.012

Boecker, H., Henriksen, G., Sprenger, T., Miederer, I., Willoch, F., Valet, M., et al. (2008). Positron emission tomography ligand activation studies in the sports sciences: measuring neurochemistry in vivo. Methods 45, 307-318. doi:10.1016/j.ymeth.2008.07.003

Brisswalter, J., Collardeau, M., and René, A. (2002). Effects of acute physical exercise characteristics on cognitive performance. Sports Med. 32, 555-566. doi:10.2165/00007256200232090-00002

Brown, S. A., and Tapert, S. F. (1999). Neuropsychological correlates of adolescent substance abuse: four-year outcomes. J. Int. Neuropsychol. Soc. 5, 481-493. doi:10.1017/S1355617799566010

Brown, S. A., Tapert, S. F., Granholm E., and Delis, D. C. (2000). Neurocognitive functioning of adolescents: effects of protracted alcohol use. Alcohol. Clin. Exp. Res. 24, 164-171. doi:10.1111/j.15300277.2000.tb04586.x

Caldwell, L. C., Schweinsburg, A. D., Nagel, B. J., Barlett, V. C., Brown, S. A., and Tapert, S. F. (2005). Gender and adolescent alcohol use disorders on BOLD (blood oxygen level dependent) response to spatial working memory. Alcohol Alcohol. 40, 194-200. doi:10.1093/alcalc/agh134

Casey, B. J., Galvan, A., and Hare, T. A. (2005). Changes in cerebral functional organization during cognitive development. Curr. Opin. Neurobiol. 15, 239-244. doi:10.1016/j.conb.2005.03.012

Casey, B. J., Getz, S., and Galvan, A. (2008). The adolescent brain. Dev. Rev. 28, 62-77. doi:10.1016/j.dr.2007.08.003

Casey, B. J., Trainor, R. J., Orendi, J. L., Schubert, A. B., Nystrom, L. E., Giedd, J. N., et al. (1997). A developmental functional MRI study of prefrontal activation during performance of a go-no-go task. J. Cogn. Neurosci. 9, 835-847. doi:10.1162/jocn.1997.9.6.835

Cha, Y. M., White, A. M., Kuhn, C. M., Wilson, W. A., and Swartzwelder, H. S. (2006). Differential effects of delta(9)-THC on learning in adolescent and adult rats. Pharmacol. Biochem. Behav. 83, 448-455. doi:10.1016/j.pbb.2006.03.006

Chaouloff, F. (1989). Physical exercise and brain monoamines: a review. Acta Physiol. Scand. 137, 1-13. doi:10.1111/j.17481716.1989.tb08715.x

Cheetham, A., Allen, N. B., Whittle, S., Simmons, J. G., Yücel, M., and Lubman, D. I. (2012). Orbitofrontal volumes in early adolescence predict initiation of cannabis use: a 4-year longitudinal and prospective study. Biol. Psychiatry 71, 684-692. doi:10.1016/j.biopsych.2011.10.029

Chen, Y. C., Prescott, C. A., Walsh, D., Patterson, D. G., Riley, B. P., Kendler, K. S., et al. (2011). Different phenotypic and genotypic presentations in alcohol dependence: age at onset matters. J. Stud. Alcohol Drugs 72 752-762.

Churchwell, J. C., Lopez-Larson, M. and Yurgelun-Todd, D. A. (2010). Altered frontal cortical volume and decision making in adolescent cannabis users. Front. Psychol. 1:225 doi:10.3389/fpsyg.2010.00225

Cloninger, C. R. (1987). Neurogenetic adaptive mechanisms in alcoholism. Science 236, 410-416. doi:10.1126/science. 2882604

Coelho, F. G., Gobbi, S., Andreatto, C. A., Corazza, D. I., Pedroso, R. V., and Santos-Galduróz, R. F. (2013). Physical exercise modulates peripheral levels of brain-derived neurotrophic factor (BDNF): a systematic review of experimental studies in the elderly. Arch. Gerontol. Geriatr. 56, 10-15. doi:10.1016/j.archger.2012.06.003

Cohen-Zion, M., Drummond, S. P. A., Padula, C. B., Winward, J., Kanady, J., Medina, K. L., et al. (2009). Sleep architecture in adolescent marijuana and alcohol users during acute and extended abstinence. Addict. Behav. 34, 967-969. doi:10.1016/j.addbeh.2009.05.011

Colcombe, S., and Kramer, A. F. (2003). Fitness effects on the cognitive function of older adults: a meta-analytic study. Psychol. Sci. 14, 125-130. doi:10.1111/1467-9280.t01-1-01430

Colcombe, S. J., Erickson, K. I., Scalf, P. E., Kim, J. S., Prakash, R., McAuley, E., et al. (2006). Aerobic exercise training increases brain volume in aging humans. J. Gerontol. A Biol. Sci. Med. Sci. 61, 1166-1170. doi:10.1093/gerona/61.11.1166

Colcombe, S. J., Kramer, A. F., Erickson, K. I., Scalf, P., McAuley, E., Cohen, N. J., et al. (2004). Cardiovascular fitness, cortical plasticity, and aging. Proc. Natl. Acad. Sci. U.S.A. 101, 3316-3321. doi:10.1073/pnas.0400266101

Coleman, L. G. Jr., He, J., Lee, J., Styner, M., and Crews, F. T. (2011). Adolescent binge drinking alters adult brain neurotransmitter gene expression, behavior, brain regional volumes, and neurochemistry in mice. Alcohol. Clin. Exp. Res. 35, 671-688. doi:10.1111/j.15300277.2010.01385.x

Cotman, C. W., and Berchtold, N. C. (2002). Exercise: a behavioral intervention to enhance brain health and plasticity. Trends Neurosci. 25, 295-301. doi:10.1016/S01662236(02)02143-4

Courtney, K. E., and Polich, J. (2010). Binge drinking effects on EEG in young adult humans. Int. J. Environ.
Res. Public Health 7, 2325-2336. doi:10.3390/ijerph7052325

Crego, A., Rodriguez-Holguín, S., Parada, M., Mota, N., Corral, M., and Cadaveira, F. (2010). Reduced anterior prefrontal cortex activation in young binge drinkers during a visual working memory task. Drug Alcohol Depend. 109, 45-56. doi:10. 1016/j.drugalcdep.2009.11.020

Dawe, S., Gullo, M. J., and Loxton, N. J. (2004). Reward drive and rash impulsiveness as dimensions of impulsivity: implications for substance misuse. Addict. Behav. 29, 1389-1405. doi:10.1016/j.addbeh.2004.06.004

De Bellis, M. D., Clark, D. B., Beers, S. R., Soloff, P. H., Boring, A. M., Hall, J., et al. (2000). Hippocampal volume in adolescent-onset alcohol use disorders. Am. J. Psychiatry 157, 737-744. doi:10.1176/appi.ajp.157.5.737

De Bellis, M. D., Narasimhan, A., Thatcher, D. L., Keshavan, M. S., Soloff, P., and Clark, D. B. (2005). Prefrontal cortex, thalamus and cerebellar volumes in adolescents and young adults with adolescent onset alcohol use disorders and comorbid mental disorders. Alcohol. Clin. Exp. Res. 29, 1590-1600. doi:10. 1097/01.alc.0000179368.87886.76

Degenhardt, L., Chiu, W. T., Sampson, N., Kessler, R. C., Anthony, J. C., Angermeyer, M., et al. (2008). Toward a global view of alcohol, tobacco, cannabis, and cocaine use: findings from the WHO World Mental Health Surveys. PLoS Med. 5:e141. doi:10.1371/journal.pmed.0050141

DeLisi, L. E., Bertisch, H. C., Szulc, K. U., Majcher, M., Brown, K., Bappal, A., et al. (2006). A preliminary DTI study showing no brain structural change associated with adolescent cannabis use. Harm. Reduct. J. 3, 17. doi:10.1186/1477-7517-3-17

Demir, B., Ulug, B., Lay Ergün, E., and Erbas, B. (2002). Regional cerebral blood flow and neuropsychological functioning in early and late onset alcoholism. Psychiatry Res. 115, 115-125. doi:10.1016/S09254927(02)00071-9

DeWit, D. J., Adlaf, E. M., Offord, D. R., and Ogborne, A. C. (2000). Age at first alcohol use: a risk factor for the development of alcohol disorders. Am. J. Psychiatry 157, 745-750. doi:10.1176/appi.ajp.157.5.745

Dik, M., Deeg, D. J., Visser, M., and Jonker, C. (2003). Early life physical activity and cognition at old age. J. Clin. Exp. Neuropsychol. 25, 643-653. doi:10.1076/jcen.25.5.643.14583 
Dom, G., Hulstijn, W., and Sabbe, B. (2006a). Differences in impulsivity and sensation seeking between early- and late-onset alcoholics. Addict. Behav. 31, 298-308. doi:10.1016/j.addbeh.2005.05.009

Dom, G., D'haene, P., Hulstijn, W., and Sabbe, B. (2006b). Impulsivity in abstinent early- and late-onset alcoholics: differences in self-report measures and a discounting task. Addiction 101, 50-59. doi:10.1111/j.13600443.2005.01270.x

Dunn, A. L., and Dishman, R. K. (1991). Exercise and the neurobiology of depression. Exerc. Sport Sci. Rev. 19, 41-98. doi:10.1249/00003677199101000-00002

Dunn, A. L., Reigle, T. G., Youngstedt, S. D., Armstrong, R. B., and Dishman, R. K. (1996). Brain norepinephrine and metabolites after treadmill training and wheel running in rats. Med. Sci. Sports Exerc. 28, 204-209. doi:10.1097/00005768199602000-00008

Dustman, R. E., Emmerson, R. Y., Ruhling, R. O., Shearer, D. E., Steinhaus, L. A., Johnson, S. C., et al. (1990). Age and fitness effects on EEG, ERPs, visual sensitivity, and cognition. Neurobiol. Aging 11, 193-200. doi:10.1016/0197-4580(90)90545-B

Eaton, L. K., Kann, L., Kinchen, S., Ross, J., Hawkins, J., Harris, W. A., et al. (2006). Youth risk behavior surveillance - United States, 2005, surveillance summaries. MMWR Surveill. Summ. 55, 1-108.

Ehlers, C. L., Phillips, E., Finnerman, G., Gilder, D., Lau, P., and Criado, J. (2007). P3 components and adolescent binge drinking in Southwest California Indians. Neurotoxicol. Teratol. 29, 153-163. doi:10.1016/j.ntt.2006.11.013

Ehrenreich, H., Rinn, T., Kunert, H. J., Moeller, M. R., Poser, W., Schilling, L., et al. (1999). Specific attentional dysfunction in adults following early start of marijuana use. Psychopharmacology (Berl.) 142, 295-301. doi:10.1007/s002130050892

Elam, M., Svensson, T. H., and Thorén, P. (1987). Brain monoamine metabolism is altered in rats following spontaneous, long-distance running. Acta Physiol. Scand. 130, 313-316. doi:10.1111/j.17481716.1987.tb08142.x

Etnier, J., Salazar, W., Landers, D., Petruzzello, S., Han, M., and Nowell, P. (1997). The influence of physical fitness and exercise upon cognitive functioning: a metaanalysis. J. Sport Exerc. Psychol. 19, 249-277.
Feldstein Ewing, S. W., Mead, H. K., Yezhuvath, U., Dewitt, S., Hutchison, K. E., and Filbey, F. M. (2012). A preliminary examination of how serotonergic polymorphisms influence brain response following an adolescent cannabis intervention. Psychiatry Res. 204, 112-116. doi:10.1016/j.pscychresns.2012. 10.011

Ferris, L. T., Williams, J. S., and Shen, C. L. (2007). The effect of acute exercise on serum brainderived neurotrophic factor levels and cognitive function. Med. Sci. Sports Exerc. 39, 728-734. doi:10.1249/mss.0b013e31802f04c7

Field, T., Diego, M., and Sanders, C. E. (2001). Exercise is positively related to adolescents' relationships and academics. Adolescence 36, 105-110.

Fontes, M. A., Bolla, K. I., Cunha, P. J., Almeida, P. P., Jungerman, F., Laranjeira, R. R., et al. (2011). Cannabis use before age 15 and subsequent executive functioning. Br. J. Psychiatry 198, 442-447. doi:10.1192/bjp.bp.110.077479

Fried, P. A., Watkinson, B., and Gray, R. (2005). Neurocognitive consequences of marihuana-a comparison with pre-drug performance. Neurotoxicol. Teratol. 27, 231-239. doi:10.1016/j.ntt.2004.11.003

Galvan, A., Hare, T. A., Parra, C. E., Penn, J., Voss, H., Glover, G., et al. (2006). Earlier development of the accumbens relative to orbitofrontal cortex might underlie risk-taking behavior in adolescents. J. Neurosci. 26, 6885-6892. doi:10.1523/JNEUROSCI.106206.2006

Gardener, M., and Steinberg, L. (2005). Peer influence on risk taking, risk preference, and risky decision making in adolescence and adulthood: an experimental study. Dev. Psychol. 41, 625-635. doi:10.1037/00121649.41.4.625

Giancola, P. R., Mezzich, A. C., and Tarter, R. E. (1998). Disruptive, delinquent and aggressive behavior in female adolescents with a psychoactive substance use disorder: relation to executive cognitive functioning. J. Stud. Alcohol 59, 560-567.

Giedd, J. N., Blumenthal, J., Jeffries, N. O., Castellanos, F. X., Liu, H., Zijdenbos, A., et al. (1999). Brain development during childhood and adolescence: a longitudinal MRI study. Nat. Neurosci. 2, 861-863. doi:10.1038/13158

Giedd, J. N., Snell, J. W., Lange, N., Rajapakse, J. C., Casey, B. J.,
Kozuch, P. L., et al. (1996a). Quantitative magnetic resonance imaging of human brain development: ages 4-18. Cereb. Cortex 6, 551-560. doi:10.1093/cercor/6.4.551

Giedd, J. N., Vaituzis, A. C., Hamburger, S. D., Lange, N., Rajapakse, J. C., Kaysen, D., et al. (1996b). Quantitative MRI of the temporal lobe, amygdala, and hippocampus in normal human development: ages 4-18 years. J. Comp. Neurol. 366, 223-230. doi:10.1002/(SICI) 1096 9861(19960304)366:2<223::AIDCNE3 >;3.0.CO;2-7

Gilligan, S. B., Reich, T., and Cloninger, C. R. (1988). Alcohol-related symptoms in heterogeneous families of hospitalized alcoholics. Alcohol. Clin. Exp. Res. 12, 671-678. doi:10.1111/j.15300277.1988.tb00263.x

Gilman, J. M., Ramchandani, V. A., Crouss, T., and Hommer, D. W. (2012). Subjective and neural responses to intravenous alcohol in young adults with light and heavy drinking patterns. Neuropsychopharmacology 37, 467-477. doi:10.1038/npp.2011.206

Gogtay, N., Giedd, J. N., Lusk, L., Hayashi, K. M., Greenstein, D. Vaituzis, A. C., et al. (2004). Dynamic mapping of human cortical development during childhood through early adulthood. Proc. Natl. Acad. Sci. U.S.A 101, 8174-8179. doi:10.1073/pnas.0402680101

Gonzalez, R., Schuster, R. M., Mermelstein, R. J., Vassileva, J., Martin, E. M., and Diviak, K. R. (2012). Performance of young adult cannabis users on neurocognitive measures of impulsive behavior and their relationship to symptoms of cannabis use disorders. J. Clin. Exp. Neuropsychol. 34, 962-976. doi:10.1080/13803395.2012.703642

Grant, J. E., Chamberlain, S. R., Schreiber, L., and Odlaug, B. L. (2012). Neuropsychological deficits associated with cannabis use in young adults. Drug Alcohol Depend. 121, 159-162. doi:10.1016/j.drugalcdep.2011. 08.015

Gruber, S. A., Dahlgren, M. K., Sagar, K. A., Gönenc, A., and Killgore, W. D. (2012). Age of onset of marijuana use impacts inhibitory processing. Neurosci. Lett. 511, 89-94. doi:10.1016/j.neulet.2012.01.039

Gruber, S. A., Silveri, M. M., Dahlgren, M. K., and Yurgelun-Todd, D. (2011). Why so impulsive? White matter alterations are associated with impulsivity in chronic marijuana smokers. Exp. Clin.
Psychopharmacol. 19, 231-242. doi:10.1037/a0023034

Hanson, K. L., Medina, K. L., Nagel, B. J., Spadoni, A. D., Gorlick, A., and Tapert, S. F. (2010a). Hippocampal volumes in adolescents with and without a family history of alcoholism. Am. J. Drug Alcohol Abuse 36, 161-167. doi:10.3109/00952991003736397

Hanson, K. L., Winward, J. L., Schweinsburg, A. D., Medina, K. L., Brown S. A., and Tapert, S. F. (2010b). Longitudinal study of cognition among adolescent marijuana users over three weeks of abstinence. Addict. Behav. 35, 970-976. doi:10.1016/j.addbeh.2010.06.012

Hanson, K. L., Medina, K. L., Padula, C. B., Tapert, S. F., and Brown, S. A. (2011). How does adolescent alcohol and drug use affect neuropsychological functioning in young adulthood: 10-year outcomes. J. Child Adolesc. Subst. Abuse 20, 135-154.

Harding, I. H., Solowij, N., Harrison, B. J., Takagi, M., Lorenzetti, V., Lubman, D. I., et al. (2012). Functional connectivity in brain networks underlying cognitive control in chronic cannabis users. Neuropsychopharmacology 37, 1923-1933. doi:10.1038/npp.2012.39

Hartley, D. E., Elsabagh, S., and File, S. E. (2004). Binge drinking and sex: effects on mood and cognitive function in healthy young volunteers. Pharmacol. Biochem. Behav. 78, 611-619. doi:10.1016/j.pbb.2004.04.027

Harvey, M. A., Sellman, J. D., Porter, R. J., and Frampton, C. M. (2007). The relationship between non-acute adolescent marijuana use and cognition. Drug Alcohol Rev. 26, 309-319. doi:10.1080/09595230701247772

Helfer, J. L., Goodlett, C. R., Greenough, W. T., and Klintsova, A. Y. (2009). The effects of exercise on adolescent hippocampal neurogenesis in a rat model of binge alcohol exposure during the brain growth spurt. Brain Res. 19, 1-11. doi:10.1016/j.brainres.2009.07.090

Heyes, M. P., Garnett, E. S., and Coates, G. (1985). Central dopaminergic activity influences rats ability to exercise. Life Sci. 36, 671-677. doi:10.1016/0024-3205(85)90172-9

Heyn, P., Abreu, B. C., and Ottenbacher, K. J. (2004). The effects of exercise training on elderly persons with cognitive impairment and dementia: a meta-analysis. Arch. Phys. Med. Rehabil. 85, 1694-1704. doi:10.1016/j.apmr.2004.03.019

Hicks, B. M., Durbin, C. E., Blonigen, D. M., Iacono, W. G., and McGue, 
M. (2012). Relationship between personality change and the onset and course of alcohol dependence in young adulthood. Addiction 107, 540-548. doi:10.1111/j.13600443.2011.03617.x

Hicks, B. M., Iacono, W. G., and McGue, M. (2010). Consequences of an adolescent onset and persistent course of alcohol dependence in men: adolescent risk factors and adult outcomes. Alcohol. Clin. Exp. Res. 34, 819-833. doi:10.1111/j.15300277.2010.01154.x

Hill, S. Y., Muddasani, S., Prasad, K., Nutche, J., Steinhauer, S. R., Scanlon, J., et al. (2007a). Cerebellar volume in offspring from multiplex alcohol dependence families. Biol. Psychiatry 61, 41-47. doi:10.1016/j.biopsych.2006.01.007

Hill, S. Y., Kostelnik, B., Holmes, B., Goradia, D., McDermott, M., Diwadkar, V., et al. (2007b). fMRI BOLD response to the eyes task in offspring from multiplex alcohol dependence families. Alcohol. Clin. Exp. Res. 31, 2028-2035. doi:10.1111/j.15300277.2007.00535.x

Hillman, C. H., Erickson, K. I., and Kramer, A. F. (2008). Be smart, exercise your heart: exercise effects on brain and cognition. Nat. Rev. Neurosci. 9, 58-65. doi:10.1038/nrn2298

Hillman, C. H., Snook, E. M., and Jerome, G. J. (2003). Acute cardiovascular exercise and executive control function. Int. J. Psychophysiol. 48, 307-314. doi:10.1016/S01678760(03)00080-1

Howard, R., Finn, P., Jose, P., and Gallagher, J. (2011). Adolescentonset alcohol abuse exacerbates the influence of childhood conduct disorder on late adolescent and early adult antisocial behaviour. $J$. Forens. Psychiatry Psychol. 23, 7-22. doi:10.1080/14789949.2011.641996

Huestegge, L., Radach, R., Kunert, H. J., and Heller, D. (2002). Visual search in long-term cannabis users with early age of onset. Prog. Brain Res. 140, 377-394. doi:10.1016/S00796123(02)40064-7

Jacobsen, L. K., Pugh, K. R., Constable, R. T., Westerveld, M., and Mencl, W. E. (2007). Functional correlates of verbal memory deficits emerging during nicotine withdrawal in abstinent adolescent marijuana users. Biol. Psychiatry 61, 31-40. doi:10.1016/j.biopsych.2006.02.014

Jacobus, J., Goldenberg, D., Wierenga, C. E., Tolentino, N. J., Liu, T. T., and Tapert, S. F. (2012). Altered cerebral blood flow and neurocognitive correlates in adolescent cannabis users. Psychopharmacology (Berl.) 222, 675-684. doi:10.1007/s00213012-2674-4

Jager, G., Block, R. I., Luijten, M., and Ramsey, N. F. (2010). Cannabis use and memory brain function in adolescent boys: a crosssectional multicenter functional magnetic resonance imaging study. J. Am. Acad. Child Adolesc. Psychiatry 49, 561-572. doi:10.1016/j.jaac.2010.02.001

Jarvis, K., DelBello, M. P., Mills, N., Elman, I., Strakowski, S. M., and Adler, C. M. (2008). Neuroanatomic comparison of bipolar adolescents with and without cannabis use disorders. J. Child Adolesc. Psychopharmacol. 18, 557-563. doi:10.1089/cap.2008.033

Jernigan, T., and Gamst, A. (2005). Changes in volume with age: consistency and interpretation of observed effects. Neurobiol. Aging 26, 1271-1274. doi:10.10 16/j.neurobiolaging.2005.05.016

Johnson, B. A., Cloninger, C. R., Roache, J. D., Bordnick, P. S., and Ruiz, P. (2000). Age of onset as a discriminator between alcoholic subtypes in a treatment-seeking outpatient population. Am. J. Addict. 9, 17-27. doi:10.1080/10550490050172191

Johnston, L. D., O’Malley, P. M., Bachman, J. G., and Schulenberg, J. E. (2009). Monitoring the Future National Survey Results on Drug Use, 1975-2008: Volume II, College Students and Adults Ages 19-50 (NIH Publication No. 09-7403). Bethesda, MD: National Institute on Drug Abuse.

Johnston, L. D., O’Malley, P. M., Bachman, J. G., and Schulenberg, J. E. (2010). Monitoring the Future National Results on Adolescent Drug Use: Overview of Key Findings, 2009 (NIH Publication No. 10-7583). Bethesda, MD: National Institute on Drug Abuse.

Johnston, L. D., O'Malley, P. M., Bachman, J. G., and Schulenberg, J. E. (2011). Marijuana use Continues to Rise Among U.S. Teens, While Alcohol use Hits Historic Lows. Ann Arbor, MI: University of Michigan News Service.

Kloos, A., Weller, R. A., Chan, R., and Weller, E. B. (2009). Gender differences in adolescent substance abuse. Curr. Psychiatry Rep. 11, 120-126. doi:10.1007/s11920-009-0019-8

Knight, J. R., Sherritt, L., Shrier, L. A., Harris, S. K., and Chang, G. (2002) Validity of the CRAFFT substance abuse screening test among adolescent clinic patients. Arch. Pediatr. Adolesc. Med. 156, 607-614.
Kolb, B., Mychasiuk, R., Muhammad, A., Li, Y., Frost, D. O., and Gibb, R. (2012). Experience and the developing prefrontal cortex. Proc. Natl. Acad. Sci. U.S.A. 16, 109 doi:10.1073/pnas.1121251109

Koskinen, S. M., Ahveninen, J., Kujala, T., Kaprio, J., O'Donnell, B. F., Osipova, D., et al. (2011). A longitudinal twin study of effects of adolescent alcohol abuse on the neurophysiology of attention and orienting. Alcohol. Clin. Exp. Res. 35, 1339-1350. doi:10.1111/j.15300277.2011.01470.x

Kramer, A. F., and Erickson, K. I. (2007). Capitalizing on cortical plasticity: influence of physical activity on cognition and brain function. Trend Cogn. Sci. (Regul. Ed.) 11, 342-348. doi:10.1016/j.tics.2007.06.009

Larimer, M. E., and Cronce, J. M. (2007). Identification, prevention, and treatment revisited individual-focused college drinking prevention strategies 1999-2006. Addict. Behav. 32, 2439-2468. doi:10.1016/j.addbeh.2007.05.006

Lee, S. S., Humphreys, K. L., Flory, K., Liu, R., and Glass, K. (2011). Prospective association of childhood attention-deficit/hyperactivity disorder (ADHD) and substance use and abuse/dependence: a meta-analytic review. Clin. Psychol. Rev. 31, 328-341. doi:10.1016/j.cpr.2011.01.006

Lenroot, R. K., and Giedd, J. N. (2006) Brain development in children and adolescents: insights from anatomical magnetic resonance imaging. Neurosci. Biobehav. Rev. 30, 718-729. doi:10.1016/j.neubiorev.2006.06.001

Lenroot, R. K., and Giedd, J. N. (2010). Sex differences in the adolescent brain. Brain Cogn. 72, 46-55. doi:10.1016/j.bandc.2009.10.008

Lenroot, R. K., Gogtay, N., Greenstein, D. K., Wells, E. M., Wallace, G. L., Clasen, L. S., et al. (2007). Sexual dimorphism of brain developmental trajectories during childhood and adolescence. Neuroimage 36, 1065-1073. doi:10.1016/ j.neuroimage.2007.03.053

Lisdahl, K. M., and Price, J. S. (2012). Increased marijuana use and gender predict poorer cognitive functioning in healthy emerging adults. $J$. Int. Neuropsychol. Soc. 18, 678-688. doi:10.1017/S1355617712000276

Lisdahl, K. M., Thayer, R., Squeglia, L., McQueeny, T. M., and Tapert, S. T. (2013). Cerebellar structure in adolescent binge drinkers. Psychiatry Res. 211, 17-23. doi:10.1016/j.pscychresns. 2012.07.009
Liston, C., Watts, R., Tottenham, N., Davidson, M. C., Niogi, S., Ulug, A. M., et al. (2006). Frontostriatal microstructure modulates efficient recruitment of cognitive control. Cereb. Cortex 16, 553-560. doi:10.1093/cercor/bhj003

López-Caneda, E., Cadaveira, F., Crego, A., Gómez-Suárez, A., Corral, M., Parada, M., et al. (2012). Hyperactivation of right inferior frontal cortex in young binge drinkers during response inhibition: a follow-up study. Addiction 107, 1796-1808. doi:10.1111/j.13600443.2012.03908.x

Lopez-Larson, M. P., Bogorodzki, P., Rogowska, J., McGlade, E., King, J. B., Terry, J., et al. (2011). Altered prefrontal and insular cortical thickness in adolescent marijuana users. Behav. Brain Res. 220, 164-172. doi:10.1016/j.bbr.2011.02.001

Lopez-Larson, M. P., Rogowska, J., Bogorodzki, P., Bueler, C. E., McGlade, E. C., and YurgelunTodd, D. A. (2012). Corticocerebellar abnormalities in adolescents with heavy marijuana use. Psychiatry Res. 202, 224-232. doi:10. 1016/j.pscychresns.2011.11.005

Lynskey, M., and Hall, W. (2000). The effects of adolescent cannabis use on educational attainment: a review. Addiction 95, 1621-1630. doi:10.1046/j.13600443.2000.951116213.x

Lyvers, M., Czerczyk, C., Follent, A. and Lodge, P. (2009). Disinhibition and reward sensitivity in relation to alcohol consumption by university undergraduates. Addict. Res. Theory 17, 668-677.

Lyvers, M., Duff, H., and Hasking, P. (2011). Risky alcohol use and age of onset of regular alcohol consumption in relation to frontal lobe indices, reward sensitivity and rash impulsiveness. Addict. Res. Theory 19, 251-259.

Ma, Q. (2008). Beneficial effects of moderate voluntary physical exercise and its biological mechanisms on brain health. Neurosci. Bull. 24, 265-270. doi:10.1007/s12264008-0402-1

Macher, R. B., and Earleywine, M. (2012). Enhancing neuropsychological performance in chronic cannabis users: the role of motivation. J. Clin. Exp. Neuropsychol. 34, 405-415. doi:10.1080/13803395.2011.646957

Marks, B. L., Madden, D. J., Bucur, B., Provenzale, J. M., White, L. E., Cabeza, R., et al. (2007). Role of aerobic fitness and aging on cerebral white matter integrity. Ann. 
N. Y. Acad. Sci. 1097, 171-174. doi:10.1196/annals.1379.022

Martin, C. S., Kaczynski, N. A., Maisto, S. A., and Tarter, R. E. (1996). Polydrug use in adolescent drinkers with and without DSM-IV alcohol abuse and dependence. Alcohol. Clin. Exp. Res. 20, 1099-1108. doi:10.1111/j.15300277.1996.tb01953.x

Mathias, C. W., Blumenthal, T. D., Dawes, M. A., Liguori, A., Richard, D. M., Bray, B., et al. (2011). Failure to sustain prepulse inhibition in adolescent marijuana users. Drug Alcohol Depend. 116, 110-116. doi:10.1016/j.drugalcdep.2010. 11.020

Maurage, P. M., Pesenti, M., Philippot, P., Joassin, F., and Campanella, S. (2009). Latent deleterious effects of binge drinking over a short period of time revealed only by electrophysiological measures. J. Psychiatry Neurosci. 34, 111-118.

McHale, S., and Hunt, N. (2008). Executive function deficits in short-term abstinent cannabis users. Hum. Psychopharmacol. 23, 409-415. doi:10.1002/hup.941

McQueeny, T., Schweinsburg, B. C., Schweinsburg, A. D., Jacobus, J., Bava, S., Frank, L. R., et al. (2009). Altered white matter integrity in adolescent binge drinkers. Alcohol. Clin. Exp. Res. 33, 1278-1285. doi:10.1111/j.15300277.2009.00953.x

McQueeny, T. M., Padula, C., Price, J., Medina, K. L., Logan, P., and Tapert, S. F. (2011). Gender effects on amygdala morphometry in adolescent marijuana users. Behav. Brain Res. 224, 128-134. doi:10.1016/j.bbr.2011.05.031

Medina, K. L., Hanson, K., Schweinsburg, A. D., Cohen-Zion, M., Nagel, B. J., and Tapert, S. F. (2007a). Neuropsychological functioning in adolescent marijuana users: subtle deficits detectable after 30 days of abstinence. J. Int. Neuropsychol. Soc. 13, 807-820. doi:10.1017/S1355617707071032

Medina, K. L., Nagel, B. J., McQueeny, T., Park, A., and Tapert, S. F. (2007b). Depressive symptoms in adolescents: associations with white matter volume and marijuana use. J. Child Psychol. Psychiatry 48, 592-600. doi:10.1111/j.14697610.2007.01728.x

Medina, K. L., Schweinsburg, A. D., Cohen-Zion, M., Nagel, B. J., and Tapert, S. F. (2007c). Effects of alcohol and combined marijuana and alcohol use during adolescence on hippocampal asymmetry.
Neurotoxicol. Teratol. 29, 141-152. doi:10.1016/j.ntt.2006.10.010

Medina, K. L., McQueeny, T., Nagel, B. J., Hanson, K., Schweinsburg, A. D., and Tapert, S. F. (2008). Prefrontal cortex volumes in adolescents with alcohol use disorders: unique gender effects. Alcohol. Clin. Exp. Res. 32, 386-394. doi:10.1111/j.15300277.2007.00602.x

Medina, K. L., McQueeny, T., Nagel, B. J., Hanson, K. L., Yang, T., and Tapert, S. F. (2009). Prefrontal morphometry in abstinent adolescent marijuana users: subtle gender effects. Addict. Biol. 14, 457-468. doi:10.1111/j.13691600.2009.00166.x

Medina, K. L., Nagel, B. J., and Tapert, S. F. (2010). Cerebellar vermis abnormality in adolescent marijuana users. Psychiatry Res. 182, 152-159. doi:10.1016/j.pscychresns.2009.12.004

Meier, M. H., Caspi, A., Ambler, A., Harrington, H., Houts, R., Keefe, R. S., et al. (2012). Persistent cannabis users show neuropsychological decline from childhood to midlife. Proc. Natl. Acad. Sci. U.S.A. 109, E2657-E2664. doi:10.1073/pnas.1206820109

Monk, C. S., McClure, E. B., Nelson, E. E., Zarahn, E., Bilder, R. M., Leibenluft, E., et al. (2003). Adolescent immaturity in attention-related brain engagement to emotional facial expressions. Neuroimage 20, 420-428. doi:10.1016/S10538119(03)00355-0

Monti, P. M., Miranda, R., Nixon, K., Sher, K. J., Swartzwelder, H. S., Tapert, S. F., et al. (2005). Adolescence: booze, brains, and behavior. Alcohol. Clin. Exp. Res. 29, 207-220. doi:10.1097/01.ALC.0000153551.11 000.F3

Moss, H. B., Kirisci, L., Gordon, H. W., and Tarter, R. E. (1994). A neuropsychologic profile of adolescent alcoholics. Alcohol. Clin. Exp. Res. 18, 159-163. doi:10.1111/j.15300277.1994.tb00897.x

Nagel, B. J., Medina, K. L., Yoshii, J., Schweinsburg, A. D., Moadab, I., and Tapert, S. F. (2006). Age related changes in prefrontal white matter volume across adolescence. Neuroreport 17, 1427-1431. doi:10.1097/01.wnr.0000233099.97 784.45

Nagel, B. J., Schweinsburg, A. D., Phan, V., and Tapert, S. F. (2005). Reduced hippocampal volume among adolescents with alcohol use disorders without psychiatric comorbidity. Psychiatry Res. 139, 181-190. doi:10. 1016/j.pscychresns.2005.05.008
Nigg, J. T., Glass, J. M., Wong, M. M., Poon, E., Jester, J. M., Fitzgerald, H. E., et al. (2004). Neuropsychological executive functioning in children at elevated risk for alcoholism: findings in early adolescence. $J$. Abnorm. Psychol. 113, 302-314. doi:10.1037/0021-843X.113.2.302

O'Shea, M., Singh, M. E., McGregor, I. S., and Mallet, P. E. (2004). Chronic cannabinoid exposure produces lasting memory impairment and increased anxiety in adolescent but not adult rats. $J$. Psychopharmacol. 18, 502-508. doi:10.1177/0269881104047277

Parada, M., Corral, M., CaamañoIsorna, F., Mota, N., Crego, A., Holguín, S. R., et al. (2011). Binge drinking and declarative memory in university students. Alcohol. Clin. Exp. Res. 35, 1475-1484. doi:10.1111/j.15300277.2011.01484.x

Parada, M., Corral, M., Mota, N., Crego, A., Rodríguez Holguín, S., and Cadaveira, F. (2012). Executive functioning and alcohol binge drinking in university students. Addict. Behav. 37, 167-172. doi:10.1016/j.addbeh.2011.09.015

Pardo, Y., Aguilar, R., Molinuevo, B., and Torrubia, R. (2007). Alcohol use as a behavioural sign of disinhibition: evidence from J.A. Gray's model of personality. Addict. Behav. 32, 2398-2403. doi:10.1016/j.addbeh.2007.02.010

Park, M. S., Sohn, S., Park, J. E., Kim, S. H., Yu, I. K., and Sohn, J. H. (2011). Brain functions associated with verbal working memory tasks among young males with alcohol use disorders. Scand. J. Psychol. 52, 1-7. doi:10.1111/j.14679450.2010.00848.x

Paus, T., Zijdenbos, A., Worsley, K., Collins, D. L., Blumenthal, J., Giedd, J. N., et al. (1999). Structural maturation of neural pathways in children and adolescents: in vivo study. Science 283, 1908-1911. doi:10.1126/science.283.5409.1908

Pereira, A. C., Huddleston, D. E., Brickman, A. M., Sosunov, A. A., Hen, R., McKhann, G. M., et al. (2007). An in vivo correlate of exercise-induced neurogenesis in the adult dentate gyrus. Proc. Natl. Acad. Sci. U.S.A. 104, 5638-5643. doi:10.1073/pnas.0611721104

Ploughman, M. (2008). Exercise is brain food: the effects of physical activity on cognitive function. Dev. Neurorehabil. 11, 236-240. doi:10.1080/17518420801997007

Pope, H. Jr., Gruber, A., Hudson, J., Cohane, G., Huestis, M., and
Yurgelun-Todd, D. (2003). Earlyonset cannabis use and cognitive deficits: what is the nature of the association? Drug Alcohol Depend. 69, 303.

Prescot, A. P., Locatelli, A. E., Renshaw, P. F., and Yurgelun-Todd, D. A. (2011). Neurochemical alterations in adolescent chronic marijuana smokers: a proton MRS study. Neuroimage 57, 69-75. doi:10. 1016/j.neuroimage.2011.02.044

Quinn, H. R., Matsumoto, I., Callaghan, P. D., Long, L. E., Arnold, J. C., Gunasekaran, N., et al. (2008). Adolescent rats find repeated $\Delta 9$ THC less aversive than adult rats but display greater residual cognitive deficits and changes in hippocampal protein expression following exposure. Neuropsychopharmacology 33, 1113-1126. doi:10.1038/sj.npp.1301475

Radak, Z., Kumagai, S., Taylor, A. W., Naito, H., and Goto, S. (2007). Effects of exercise on brain function: role of free radicals. Appl. Physiol. Nutr. Metab. 32, 942-946. doi:10.1139/H07-081

Raphael, D. (2013). Adolescence as a gateway to adult health outcomes. Maturitas 75, 137-141. doi:10.1016/j.maturitas.2013.03.013

Read, J. P., Merrill, J. E., Kahler, C. W., and Strong, D. R. (2007). Predicting functional outcomes among college drinkers: reliability and predictive validity of the Young Adult Alcohol Consequences Questionnaire. Addict. Behav. 32, 2597-2610. doi:10.1016/j.addbeh.2007.06.021

Ridenour, T. A., Tarter, R. E., Reynolds, M., Mezzich, A., Kirisci, L., and Vanyukov, M. (2009). Neurobehavior disinhibition, parental substance use disorder, neighborhood quality and development of cannabis use disorder in boys. Drug Alcohol Depend. 102, 71-77. doi:10. 1016/j.drugalcdep.2009.01.009

Rubino, T., Realini, N., Braida, D. Guidi, S., Capurro, V., Viganò, D., et al. (2009). Changes in hippocampal morphology and neuroplasticity induced by adolescent THC treatment are associated with cognitive impairment in adulthood. Hippocampus 19, 763-772. doi:10.1002/hipo. 20554

Rubino, T., Vigano, D., Realini, N., Guidali, C., Braida, D., Capurro, V., et al. (2008). Chronic delta 9-tetrahydrocannabinol during adolescence provokes sex-dependent changes in the emotional profile in adult rats: behavioral and biochemical correlates. 
Neuropsychopharmacology 33, 2760-2771. doi:10.1038/sj.npp.130 1664

Sakurai, T., Izawa, T., Kizaki, T., Ogasawara, J. E., Shirato, K., Imaizumi, K., et al. (2009). Exercise training decreases expression of inflammation-related adipokines through reduction of oxidative stress in rat white adipose tissue. Biochem. Biophys. Res. Commun. 379, 605-609. doi:10.1016/j.bbrc.2008.12.127

Scaife, J. C., and Duka, T. (2009). Behavioural measures of frontal lobe function in a population of young social drinkers with binge drinking pattern. Pharmacol. Biochem. Behav. 93, 354-362. doi:10.1016/j.pbb.2009.05.015

Schneider, M., and Koch, M. (2003). Chronic pubertal but not adult chronic cannabinoid treatment impairs sensorimotor gating, recognition memory and performance in a progressive ratio task in adult rats. Neuropsychopharmacology 28, 1760-1790. doi:10.1038/sj.npp.1300225

Schuster, R. M., Crane, N. A., Mermelstein, R., and Gonzalez, R. (2012). The influence of inhibitory control and episodic memory on the risky sexual behavior of young adult cannabis users. J. Int. Neuropsychol. Soc. 18, 827-833. doi:10.1017/S1355617712000586

Schwartz, R. H., Gruenewald, P. J., Klitzner, M., and Fedio, P. (1989). Short-term memory impairment in cannabis-dependent adolescents. Am. J. Dis. Child. 143, 1214-1219.

Schweinsburg, A. D., McQueeny, T., Nagel, B. J., Eyler, L. T., and Tapert, S. F. (2010a). A preliminary study of functional magnetic resonance imaging response during verbal encoding among adolescent binge drinkers. Alcohol 44, 111-117. doi:10.1016/j.alcohol.2009. 09.032

Schweinsburg, A. D., Schweinsburg, B. C., Medina, K. L., McQueeny, T., Brown, S. A., and Tapert, S. F. (2010b). The influence of recency of use on fMRI response during spatial working memory in adolescent marijuana users. J. Psychoactive Drugs 42, 401-412. doi:10. 1080/02791072.2010.10400703

Schweinsburg, A. D., Nagel, B. J., Schweinsburg, B. C., Park, A., Theilmann, R. J., and Tapert, S. F. (2008). Abstinent adolescent marijuana users show altered fMRI response during spatial working memory. Psychiatry Res. 163, 40-51. doi:10. 1016/j.pscychresns.2007.04.018
Schweinsburg, A. D., Paulus, M. P., Barlett, V. C., Killeen, L. A., Caldwell, L. C., Pulido, C., et al. (2004). An FMRI study of response inhibition in youths with a family history of alcoholism. Ann. N. Y. Acad. Sci. 1021, 391-394. doi:10.1196/annals.1308.050

Sher, K. J., Martin, E. D., Wood, P. K., and Rutledge, P. C. (1997). Alcohol use disorders and neuropsychological functioning in first-year undergraduates. Exp. Clin. Psychopharmacol. 5, 304-315. doi:10.1037/10641297.5.3.304

Sibley, B., and Etnier, J. (2003). The relationship between physical activity and cognition in children: a meta-analysis. Pediatr. Exerc. Sci. 15, 243-256.

Silveri, M. M., Jensen, J. E., Rosso, I. M., Sneider, J. T., and Yurgelun-Todd, D. A. (2011). Preliminary evidence for white matter metabolite differences in marijuana-dependent young men using 2D J-resolved magnetic resonance spectroscopic imaging at 4 Tesla. Psychiatry Res. 191, 201-211. doi:10.1016/j.pscychresns.2010. 10.005

Sim, Y. J., Kim, H., Shin, M. S., Chang, H. K., Shin, M. C., Ko, I. G., et al. (2008). Effect of postnatal treadmill exercise on c-Fos expression in the hippocampus of rat pups born from the alcohol-intoxicated mothers. Brain Dev. 30, 118-125. doi:10.1016/j.braindev.2007.07.003

Smith, A. M., Longo, C. A., Fried, P. A., Hogan, M. J., and Cameron, I. (2010). Effects of marijuana on visuospatial working memory: an fMRI study in young adults. Psychopharmacology (Berl.) 210, 429-438. doi:10.1007/s00213010-1841-8

Solowij, N., Jones, K. A., Rozman, M. E., Davis, S. M., Ciarrochi, J., Heaven, P. C., et al. (2011). Verbal learning and memory in adolescent cannabis users, alcohol users and nonusers. Psychopharmacology (Berl.) 216, 131-144. doi:10.1007/s00213011-2203-x

Solowij, N., Jones, K. A., Rozman, M. E., Davis, S. M., Ciarrochi, J., Heaven, P. C., et al. (2012). Reflection impulsivity in adolescent cannabis users: a comparison with alcoholusing and non-substance-using adolescents. Psychopharmacology (Berl.) 219, 575-586. doi:10.1007/s00213011-2486-y

Sowell, E. R., Thompson, P., Leonard, C. M., Welcome, S. E., Kan, E., and Toga, A. W. (2004). Longitudinal mapping of cortical thickness and brain growth in normal children. J. Neurosci. 24, 8223-8231. doi:10.1523/JNEUROSCI.179804.2004

Sowell, E. R., Thompson, P. M., Holmes, C. J., Jernigan, T. L., and Toga, A. W. (1999). In vivo evidence for post adolescent brain maturation in frontal and striatal regions. Nat. Neurosci. 2, 859-861. doi:10.1038/13154

Sowell, E. R., Trauner, D. A., Gamst, A., and Jernigan, T. L. (2002). Development of cortical and subcortical brain structures in childhood and adolescence: a structural MRI study. Dev. Med. Child Neurol. 44, 4-16. doi:10.1017/S0012162201001591

Spadoni, A. D., Norman, A. L., Schweinsburg, A. D., and Tapert, S. F. (2008). Effects of family history of alcohol use disorders on spatial working memory BOLD response in adolescents. Alcohol. Clin. Exp. Res. 32, 1135-1145. doi:10.1111/j.15300277.2008.00694.x

Spear, L. P. (2000). The Adolescent Brain and Age-Related Behavioral Manifestations. New York, NY: Norton \& Company, Inc.

Spear, L. P. (2010). The behavioral neuroscience of adolescence. Neurosci. Biobehav. Rev. 24, 417-463. doi:10. 1016/S0149-7634(00)00014-2

Squeglia, L. M., Schweinsburg, A. D., Pulido, C., and Tapert, S. F. (2011). Adolescent binge drinking linked to abnormal spatial working memory brain activation: differential gender effects. Alcohol. Clin. Exp. Res. 35, 1831-1841. doi:10.1111/j.15300277.2011.01527.x

Squeglia, L. M., Sorg, S. F., Schweinsburg, A. D., Wetherill, R. R., Pulido, C., and Tapert, S. F. (2012). Binge drinking differentially affects adolescent male and female brain morphometry. Psychopharmacology (Berl.) 220, 529-539. doi:10.1007/s00213-011-2500-4

Sullivan, J. L., Baenziger, J. C., Wagner, D. L., Rauscher, F. P., Nurnberger, J. I. Jr., and Holmes, J. S. (1990). Platelet MAO in subtypes of alcoholism. Biol. Psychiatry 27, 911-922. doi:10.1016/0006-3223(90)90473-F

Tait, R. J., Mackinnon, A., and Christensen, H. (2011). Cannabis use and cognitive function: 8-year trajectory in a young adult cohort. Addiction 106, 2195-2203. doi:10.1111/j.13600443.2011.03574.x

Tapert, S. F., Baratta, M. V., Abrantes, A. M., and Brown, S. A. (2002a). Attention dysfunction predicts substance involvement in community youths. J. Am. Acad. Child Adolesc. Psychiatry 41, 680-686. doi:10.1097/00004583200206000-00007
Tapert, S. F., Granholm, E., Leedy, N. G., and Brown, S. A. (2002b). Substance use and withdrawal: neuropsychological functioning over 8 years in youth. J. Int. Neuropsychol. Soc. 8, 873-883. doi:10.1017/S1355617702870011

Themanson, J. R., Hillman, C. H., and Curtin, J. J. (2006). Age and physical activity influences on action monitoring during task switching. Neurobiol. Aging 27, 1335-1345. doi:10.1016/j.neurobiolaging.2005. 07.002

Tapert, S. F., Brown, G. G., Kindermann, S. S., Cheung, E. H., Frank, L. R., and Brown, S. A. (2001). fMRI measurement of brain dysfunction in alcohol-dependent young women. Alcohol. Clin. Exp. Res. 25, 236-245. doi:10.1111/j.15300277.2001.tb02204.x

Tapert, S. F., and Brown, S. A. (1999). Neuropsychological correlates of adolescent substance abuse: four year outcomes. $J$. Int. Neuropsychol. Soc. 5, 481-493. doi:10.1017/S1355617799566010

Tapert, S. F., and Brown, S. A. (2000). Substance dependence, family history of alcohol dependence, and neuropsychological functioning in adolescence. Addiction 95, 1043-1053. doi:10.1046/j.13600443.2000.95710436.x

Tapert, S. F., Schweinsburg, A. D., Barlett, V. C., Brown, S. A., Frank, L. R., Brown, G. G., et al. (2004). Blood oxygen level dependent response and spatial working memory in adolescents with alcohol use disorders. Alcohol. Clin. Exp. Res. 28, 1577-1586. doi:10.1097/01.ALC.0000141812.81 234.A6

Tapert, S. F., Schweinsburg, A. D., Drummond, S. P., Paulus, M. P. Brown, S. A., Yang, T. T., et al. (2007). Functional MRI of inhibitory processing in abstinent adolescent marijuana users. Psychopharmacology (Berl.) 194, 173-183. doi:10.1007/s00213-007-0823-y

Themanson, J. R., and Hillman, C. H. (2006). Cardiorespiratory fitness and acute aerobic exercise effects on neuroelectric and behavioral measures of action monitoring. Neuroscience 141, 757-767. doi:10.1016/j.neuroscience.2006. 04.004

Thoma, R. J., Monnig, M. A., Lysne, P. A., Ruhl, D. A., Pommy, J. A., Bogenschutz, M., et al. (2011). Adolescent substance abuse: the effects of alcohol and marijuana on neuropsychological performance. Alcohol. Clin. Exp. Res. 
35, 39-46. doi:10.1111/j.15300277.2010.01320.x

Timinkul, A., Kato, M., Omori, T., Deocaris, C. C., Ito, A., Kizuka, T., et al. (2008). Enhancing effect of cerebral blood volume by mild exercise in healthy young men: a near-infrared spectroscopy study. Neurosci. Res. 61, 242-248. doi:10.1016/j.neures.2008.03.012

Townshend, J. M., and Duka, T. (2005). Binge drinking, cognitive performance and mood in a population of young social drinkers. Alcohol. Clin. Exp. Res. 29, 317-325. doi:10.1097/ 01.ALC.0000156453.05028.F5

Vaidya, J. G., Block, R. I., O'Leary, D. S., Ponto, L. B., Ghoneim, M. M., and Bechara, A. (2012). Effects of chronic marijuana use on brain activity during monetary decision-making. Neuropsychopharmacology 37, 618-629. doi:10.1038/npp.2011.227

Varma, V. K., Basu, D., Malhotra, A., Sharma, A., and Mattoo, S. K. (1994). Correlates of early- and late-onset alcohol dependence. Addict. Behav. 19, 609-619. doi:10.1016/0306-4603(94)90016-7

von Knorring, A.-L., Bohman, M., von Knorring, L., and Oreland, L.
(1985). Platelet MAO activity as a biological marker in subgroups of alcoholism. Acta Psychiatr. Scand. 72, 51-58. doi:10.1111/j.16000447.1985.tb02570.x

Waters, R. P., Emerson, A. J., Watt, M. J., Forster, G. L., Swallow, J. G., and Summers, C. H. (2005). Stress induces rapid changes in central catecholaminergic activity in Anolis carolinensis: restraint and forced physical activity. Brain Res. Bull. 67, 210-218. doi:10.1016/j.brainresbull. 2005.06.029

Werch, C. C., Moore, M. J., DiClemente, C. C., Bledsoe, R., and Jobli, E. (2005). A multihealth behavior intervention integrating physical activity and substance use prevention for adolescents. Prev. Sci. 6, 213-226. doi:10.1007/s11121005-0012-3

White, H. R., Marmorstein, N. R., Crews, F. T., Bates, M. E., Mun, E. Y., and Loeber, R. (2011). Associations between heavy drinking and changes in impulsive behavior among adolescent boys. Alcohol. Clin. Exp. Res. 35, 295-303. doi:10.1111/j.15300277.2010.01345.x

Wilens, T. E., Martelon, M., Joshi, G., Bateman, C., Fried, R., Petty,
C., et al. (2011). Does ADHD predict substance-use disorders? A 10-year follow-up study of young adults with ADHD. J. Am. Acad. Child Adolesc. Psychiatry 50, 543-553. doi:10.1016/j.jaac.2011. 01.021

Wilson, W., Mathew, R., Turkington, T., Hawk, T., Coleman, R. E., and Provenzale, J. (2000). Brain morphological changes and early marijuana use: a magnetic resonance and positron emission tomography study. J. Addict. Dis. 19, 1-22. doi:10.1300/J069v19n01_01

Winnail, S. D., Valois, R. F., McKeown, R. E., Saunders, R. P., and Pate, R. R. (1995). Relationship between physical activity level and cigarette, smokeless tobacco, and marijuana use among public high school adolescents. J. Sch. Health 65, 438-442. doi:10.1111/j.17461561.1995.tb08209.x

Xiao, L., Bechara, A., Gong, Q., Huang, X., Li, X., Xue, G., et al. (2012). Abnormal affective decision making revealed in adolescent binge drinkers using a functional magnetic resonance imaging study. Psychol. Addict. Behav. doi:10.1037/a002 7892. [Epub ahead of print].
Conflict of Interest Statement: The authors declare that the research was conducted in the absence of any commercial or financial relationships that could be construed as a potential conflict of interest.

Received: 19 March 2013; paper pending published: 15 April 2013; accepted: 30 May 2013; published online: 01 July 2013. Citation: Lisdahl KM, Gilbart ER, Wright NE and Shollenbarger S (2013) Dare to delay? The impacts of adolescent alcohol and marijuana use onset on cognition, brain structure, and function. Front. Psychiatry 4:53. doi: 10.3389/fpsyt.2013.00053

This article was submitted to Frontiers in Addictive Disorders and Behavioral Dyscontrol, a specialty of Frontiers in Psychiatry.

Copyright (c) 2013 Lisdahl, Gilbart, Wright and Shollenbarger. This is an open-access article distributed under the terms of the Creative Commons Attribution License, which permits use, distribution and reproduction in other forums, provided the original authors and source are credited and subject to any copyright notices concerning any third-party graphics etc. 